\title{
Nutrient Pumping by Submesoscale Circulations in the Mauritanian Upwelling System
}

\author{
P. J. Hosegood ${ }^{\mathrm{a}}$, P. D. Nightingale ${ }^{\mathrm{b}}$, A. P. Rees ${ }^{\mathrm{b}}$, C. E. Widdicombe ${ }^{\mathrm{b}}$, E.

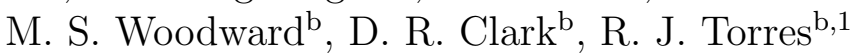 \\ ${ }^{a}$ Plymouth University, Drake Circus, Plymouth, PL4 8AA \\ ${ }^{b}$ Plymouth Marine Laboratory, Prospect Place, The Hoe, Plymouth, PL1 3DH
}

\begin{abstract}
Observations made within a cold filament in the Mauritanian upwelling system demonstrate that intense submesoscale circulations at the peripheral edges of the filament are likely responsible for anomalously high levels of observed primary productivity by resupplying nutrients to the euphotic zone. Measurements made on the shelf within the recently upwelled water reveal that primary production (PP) of $8.2 \mathrm{gC} / \mathrm{m}^{-2}$ day $^{-1}$ was supported by nitrate concentrations $(\mathrm{NC})$ of $8 \mathrm{mmol} \mathrm{m} \mathrm{m}^{-3}$. Towards the front that defined the edge of the filament containing the upwelled water as it was transported offshore, PP dropped to $1.6 \mathrm{gC} \mathrm{m}^{-2}$ day $^{-1}$ whilst $\mathrm{NC}$ dropped to $5.5 \mathrm{mmol} \mathrm{m}^{-3}$. Thus, whilst the observed nutrients on the shelf accounted for $90 \%$ of new production, this value dropped to $\sim 60 \%$ near the filament's front after accounting for vertical turbulent fluxes and Ekman pumping. We demonstrate that the $\mathrm{N}^{15}$ was likely to have been supplied at the front by submesoscale circulations that were directly measured as intense vertical velocities $\geq 100$ $m$ day $^{-1}$ by a drifting acoustic Doppler current profiler that crossed a submesoscale surface temperature front. At the same time, a recently released tracer was subducted out of the mixed layer within 24 hours of release, providing direct evidence that the frontal circulations were capable of accessing the resevoir of nutrients beneath the pycnocline. The susceptibility of the filament edge to submesoscale instabilities was demonstrated by $O(1)$ Rossby numbers at horizontal scales of $1-10 \mathrm{~km}$. The frontal circulations are consistent with instabilities arising from a wind-driven nonlinear Ekman buoyancy flux generated by the persistent northerly wind stress that has a down-front
\end{abstract}

\footnotetext{
${ }^{1}$ Corresponding author
} 
component at the northern edge of the inshore section of the filament. The prevalence of submesoscale instabilities and their associated vertical circulations are proposed to be a key mechanism operating at sub-grid scales and sustaining new production throughout the upwelling system.

Keywords: Mauritanian upwelling system, submesoscale circulation, nutrient fluxes, filament, subduction

\section{Introduction}

Nutrients play a key role in stimulating primary production within the euphotic ocean. Where dynamic processes such as eddy pumping (McGillicuddy et al., 2007) and frontal processes inject nutrients into the euphotic zone, productivity is enhanced, whereas in stratified regions where vertical exchange is limited, biological productivity is low. Understanding the processes that regulate this vertical exchange is key to understanding not just the initial stimulus provided to the phytoplankton community by the injection of nutrients but also the ongoing production that can be sustained by a persistent resupply of nutrients from beneath the euphotic zone. Similarly, the organically bound nutrients are eventually remineralised back into their inorganic forms at depth following export from the surface layers; the rate at which this is achieved is directly proportional to the vertical exchanges processes occurring across the base of the surface mixed layer and has global implications for the export of carbon to the deep ocean.

Within eastern boundary currents in the northern hemisphere seasonal or persistent northerly wind stress drives the coastal upwelling of cold, nutrient rich water to the surface where it is separated from the warmer offshore water by a sharp front (Ikeda and Emery, 1984; Capet et al., 2008a; Meunier et al., 2012). Within the euphotic zone near the surface, the combination of light availability and high nutrient concentrations inshore of the front promotes conditions favourable for primary production. Highest production occurs within the mid-shelf region (Huntsman and Barber, 1977); nearer to the coast, turbidity reduces light penetration whereas further offshore nutrient levels decline following uptake by the planktonic community. The globally important high levels of carbon fixation achieved within such upwelling systems make it necessary to understand the dynamics that control both the initial supply of nutrients to the euphotic zone though upwelling, their resupply by cross-front exchange, and their distribution throughout the upper 
ocean in response to vertical mixing processes.

The regional dynamical context of upwelling systems is dominated by the stability and structure of the coastal front separating the nutrient rich upwelled water from the warmer, stratified offshore water within which nutrients are typically depleted and thus primary production limited (Gruber et al., 2011). Numerous studies have demonstrated that coastal fronts formed in response to upwelling are subject to baroclinic instabilities that lead to the formation of mesoscale filaments within which the upwelled water is transported hundreds of kilometres offshore. The role of topography in destabilizing upwelling fronts remains subject to some debate but has been cited as a key factor (Narimousa and Maxworthy, 1989) due to the persistent presence of filaments at topographic features such as promontories and headlands (Meunier et al., 2012).

The mesoscale environment typical of the filaments is characterised by small Rossby Numbers, $R o=\zeta / f$, where $\zeta=\frac{\partial v}{\partial x}-\frac{\partial u}{\partial y}$ is the relative vorticity and $f$ is the local Coriolis parameter. For small $R o$ the flow is geostrophically balanced and constrained to flow along the front that bounds the filament. A reduced cross-front exchange inhibits the resupply of nutrients to the filaments and thus new production in the upwelling filament is limited by the magnitude of the initial injection of nutrients. As the upwelled water is transported offshore, new production draws down the nutrients, reducing their concentration and the new production that can be supported by them. Nutrients can be replaced by vertical fluxes arising from turbulent mixing across the mixed layer base and Ekman pumping, for example as suggested for the South China Sea where the two mechanisms combined control regional growth in the phytoplankton community (Li et al., 2016). As Ro approaches unity, however, a different class of dynamics referred to as submesoscales emerges and leads to the loss of geostrophic control of large scale fronts and the initiation of cross-frontal exchange by three-dimensional motions.

Characterised by length scales of $1-10 \mathrm{~km}$ and evolution timescales of $O$ (1 day), submesoscales trigger vertical velocities an order of magnitude larger than the $O\left(10 \mathrm{~m} \mathrm{day}^{-1}\right)$ associated with the mesoscale (Mahadevan and Tandon, 2006). They have been implicated in catalysing the supply of nutrients to the surface at frontal zones (Levy et al., 2001; Lévy et al., 2012) and elevating vertical buoyancy fluxes by slumping lateral density fronts at the periphery of eddies, thereby creating a patchy bloom environment within the north Atlantic 20-30 days earlier than would occur through heating alone (Mahadevan et al., 2012). Within eastern boundary current upwelling 
systems, submesoscales have been demonstrated to be potentially important at the periphery of filaments where the locally enhanced vertical velocities may resupply nutrients to the surface layers within the upward branch of the circulation and permit cross-front exchange in a manner not permitted at low Rossby numbers (Capet et al., 2008a,b). Similarly, the downward branch of the submesoscale circulation exports phytoplankton and has been suggested to dominate over nitrate input within the upward branch in coastal upwelling systems (Lathuiliere et al., 2010). Observations of this process remain scarce, however.

To address this knowledge gap, we present in this paper results from the ICON (The Impact of Coastal upwelling on the air-sea exchange of climatically important gases) cruise conducted between April 15 - May 16, 2009 in the Cap Blanc region (Fig. 1). The aim of the ICON cruise, which was a component of the UK contribution to SOLAS (Surface Ocean Lower Atmosphere Study) was to determine the coastal and shelf influence on microbiological activity and chemical interactions in an eastern boundary current upwelling system. Observations of nutrient concentrations and new production within a mesoscale filament created by upwelling and subsequent eddy-interaction reveal a higher level of productivity than can be explained by the initial supply of nutrients and subsequent draw-down. We show from direct observations that the regional environment is conducive to the generation of submesoscale instabilities at the filament periphery due to a loss of geostrophic balance. The resulting three-dimensional circulations are then potentially responsible for resupplying additional nutrients to the water within the filament and maintaining higher levels of new production than can be explained by the initial nutrient supply at the coast.

The paper is structured as follows; we firstly provide the experimental details, of which many are described in Meunier et al. (2012) such that we here provide only the additional context necessary to understand the observations presented in this paper. Particular attention is given to explaining the estimates of new production and nutrient uptake. We then present the results in three subsections to demonstrate the mismatch of nutrients and new production within the filament, the structure of the filament edges that render them susceptible to submesoscale instabilities, and finally the direct evidence for energetic vertical circulations associated with the frontal structures within the region. The implications of our results are then discussed before conclusions are drawn in the final section. 


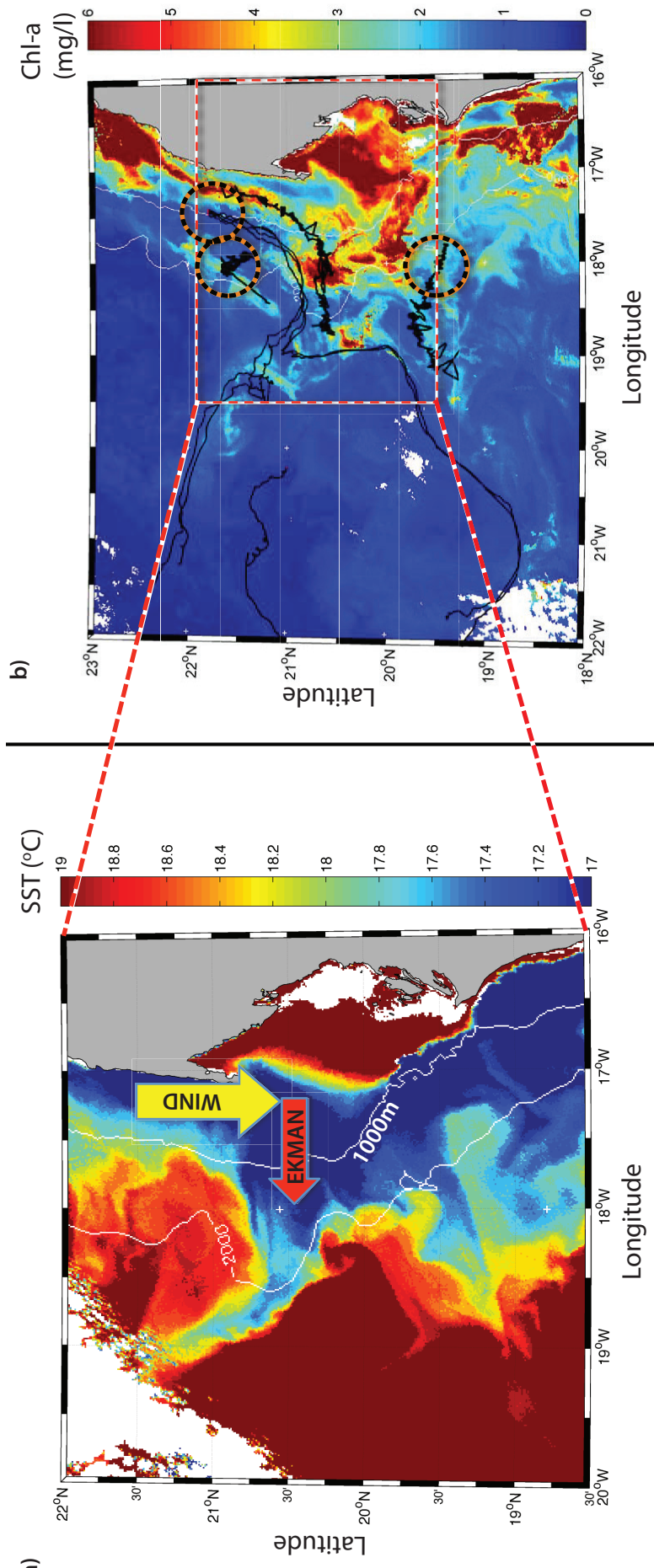

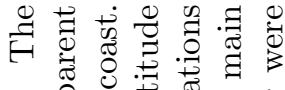

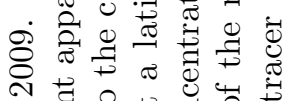

귱워

N

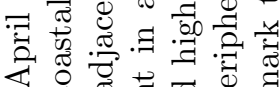

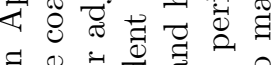

。:

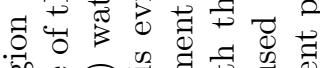

屯o

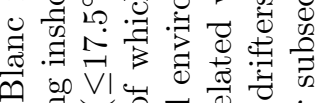

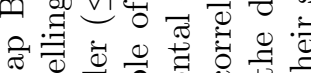

है

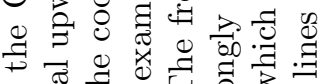

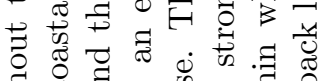

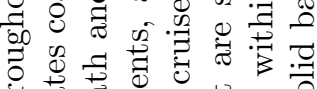

焉

荡.

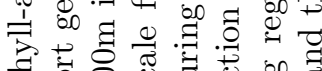

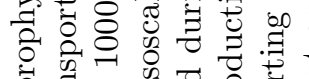

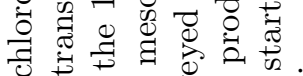

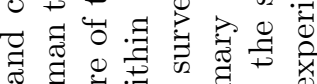

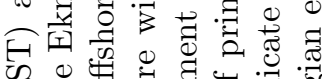

全

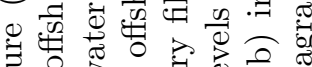

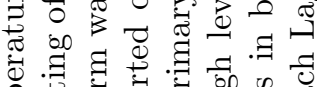

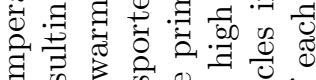

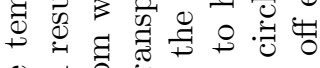

$\mathcal{O}=0$

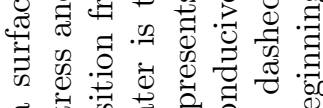

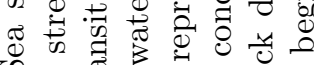

क.

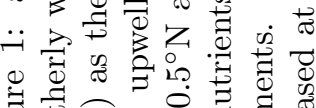

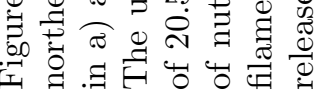




\section{Experimental details and methods}

\subsection{Oceanographic observations}

The ICON cruise was conducted aboard the RRSDiscovery over the period $t=105-131$, where $t$ is decimal year day 2009. The study region encompassed the upwelling system off the coast of Cap Blanc where wind stress was consistently directed to the south and thus generated an eastward offshore Ekman transport at the surface. The mechanisms leading to the formation of upwelling filaments has been discussed in a recent paper (Meunier et al., 2012) but can be summarized as an interaction between the external eddy field, topographic effects and the upwelled water. The region is situated within the boundary between salty North Atlantic Central Water (NACW) and the fresher South Atlantic Central Water (SACW). A zonal front forms between the water masses across the tropical north Atlantic but reorientates itself to a south-west/north-east heading near the African coast where it is referred to as the Cap Verde Frontal Zone (CVFZ). Despite a relatively weak density signature associated with the largely compensated front, baroclinic along-front jets inhibit cross-frontal exchange although the interleaving of water masses has been observed to facilitate the large-scale cross-front exchange of properties (Perez-Rodriguez et al., 2001; Martínez-Marrero et al., 2008).

Two different sampling strategies were employed throughout the cruise and are illustrated in Fig. 2. To map the three-dimensional structure and physical properties of the filaments, ship-based towed conductivity-temperaturedepth (CTD) and vessel-mounted acoustic Doppler current profiler (ADCP) surveys were undertaken. To monitor the temporal evolution of recently upwelled water, Lagrangian measurements were made of a parcel of water after releasing an inert tracer. Each approach is outlined below.

\subsubsection{Ship-based surveys}

Ship-based quasi-synoptic filament surveys consisted of multiple transects that were orientated perpendicular to the principal axis of the filament and aimed to cross the fronts on each side. Standard CTD parameters were measured using the Moving Vessel Profiler (MVP). The MVP consists of a fish that houses an Applied Microsystems Laboratory (AML) micro-CTD sampling at $25 \mathrm{~Hz}$, AML micro-dissolved oxygen and Satlantic irradiance sensors, and Chelsea Instruments MiniTracka fluorometer. The fish free-falls at a vertical rate of $1 \mathrm{~m} \mathrm{~s}^{-1}$ to a depth of $350 \mathrm{~m}$ before being recovered to 
the surface whilst the ship is underway. At a speed of 8 knots, a complete profiling cycle that includes both the downward and upward profiles (the former is vertical but the latter profile is oblique and near horizontal during recovery throughout the upper $50 \mathrm{~m}$ ) was completed during a horizontal distance of $\leq 2 \mathrm{~km}$. Data are subsequently gridded to $1 \mathrm{~km}$ horizontal and $1 \mathrm{~m}$ vertical resolution using the Barnes algorithm (Barnes, 1994). Velocity measurements were acquired using the hull-mounted $150 \mathrm{kHz}$ RDI ADCP as $8 \mathrm{~m}$ vertical bins to a depth of typically $320 \mathrm{~m}$ and averaged to 10 minute ensembles.

\subsubsection{Lagrangian observations}

A Lagrangian reference frame was employed to monitor the temporal evolution of the near-surface biogeochemical regime and its response to the injection of nutrients following upwelling. At the beginning of each Lagrangian experiment, of which there were three during the cruise and are henceforth referred to as Patches 1-3, a quantity of $\mathrm{SF}_{6}$ tracer was released within the surface mixed layer around a drogued drifter. The purpose of the $\mathrm{SF}_{6}$, which is an inert tracer, was to enable the verification of the patch location, properties and evolution by monitoring its concentration at a depth of $5 \mathrm{~m}$ where the ship's intake was located and during vertical casts. The tracer deployment and $\mathrm{SF}_{6}$ analysis followed those used in Nightingale et al. (2000). The origin of each patch was defined by the position of the central drogued drifter equipped with a radio transmitter that reported its location back to the ship at 5 minute intervals. Four further drifters were positioned at each of the corners of the initial $\mathrm{SF}_{6}$ release so that the whole patch could be constantly monitored from the ship. The centre of the patch was estimated following the nighttime sampling as the centre of mass of the $\mathrm{SF}_{6}$ (Loucaides et al., 2012). The centre of the patch was then the location where vertical microstructure profiles and water samples were obtained at regular intervals during the following daytime.

Immediately following each release of the tracer, two drogued and instrumented drifters were deployed. Each drifter was equipped with a surface satellite tracked beacon and a drogue of $6 \mathrm{~m}$ length between a depth of 9-14 $\mathrm{m}$ following standard WOCE specification. The primary drifter was equipped with a Wirewalker (Pinkel et al., 2010) on which was mounted a RBR CTD. The Wirewalker repeatedly ascends to the surface under its own buoyancy before being pulled back to its starting depth of $70 \mathrm{~m}$ by a ratchet mechanism driven by surface wave action. Vertical CTD profiles were thereby obtained 
every 10 minutes approximately during the ascent of the Wirewalker whilst the drifter was advected horizontally by the mean flow at $15 \mathrm{~m}$ depth. The CTD sampled at $6 \mathrm{~Hz}$; at an ascent rate of approximately $0.2 \mathrm{~m} \mathrm{~s}^{-1}$, raw data were obtained with a vertical resolution of $0.03 \mathrm{~m}$.

The second drifter was equipped with a downward looking $600 \mathrm{kHz}$ RDI Broadband ADCP located at $20 \mathrm{~m}$ depth, immediately beneath the drogue and isolated from surface motion by using a rubber chord of 3 inch diameter to attach the surface buoyancy to the drogue. A $1.5 \mathrm{~m}^{2}$ square plate mounted on the top of the submersible ensured the horizontal orientation of the platform. The ADCP was set to sample in Mode 12 with 3 pings per 3 second ensemble in $0.5 \mathrm{~m}$ vertical bins. Maximum range was $44 \mathrm{~m}$ from the instrument such that with a $2.2 \mathrm{~m}$ blanking distance, velocity measurements were obtained between 24-68 m. The vertical velocities were adjusted for the ADCP vertical movement prior to averaging the data into 10 minute ensembles.

CTD water samples and microstructure profiles were acquired during daytime throughout each Lagrangian experiment. The microstructure profiles acquired with the ISW Microstructure Sensor System (MSS) provide estimates of the dissipation rate of turbulent kinetic energy, $\epsilon=7.5 \mu\left\langle\left(\frac{\partial u}{\partial z}\right)\right\rangle$, where the angle brackets denote spatial averaging over typically $1 \mathrm{~m}$ and $u$ represents the turbulent velocity component . The vertical eddy diffusivity was then computed following Osborn (1980) as $K_{z}=\Gamma \frac{\epsilon}{N^{2}}$ where $\Gamma=0.2$ is the mixing efficiency and $N=\sqrt{-\frac{g}{\rho_{o}} \frac{\partial \rho}{\partial z}}$ is the Brunt-Vaisala frequency. Vertical turbulent nutrient fluxes were then estimated as $F_{n u t}=K_{z} \frac{\partial(N u t)}{\partial z}$ where $N u t$ is the observed nutrient concentration from the CTD water samples and $K_{z}$ is estimated as the mean value across the base of the mixed layer.

Within this paper we focus on a subset of observations to demonstrate the potential role played by submesoscales in supplying nutrients at the peripheral edges of filaments. We use primarily the results from Patches 1 and 2 , corresponding to the periods $t=113-120$ and $t=128-130$, respectively, and from the survey of the primary filament between $t=120-125$ within which Patch 1 was carried out. Within the Discussion we briefly refer to patch 3 for which Lagrangian measurements were made but for which no ship-based filament survey was possible due to the malfunction of the MVP.

\subsection{Remote sensing}

Sea surface temperature (SST) data were provided by the NERC Earth Observation Data Acquisition and Analysis Service (NEODAAS) through- 


\section{$\mathrm{SST}\left({ }^{\circ} \mathrm{C}\right)$}

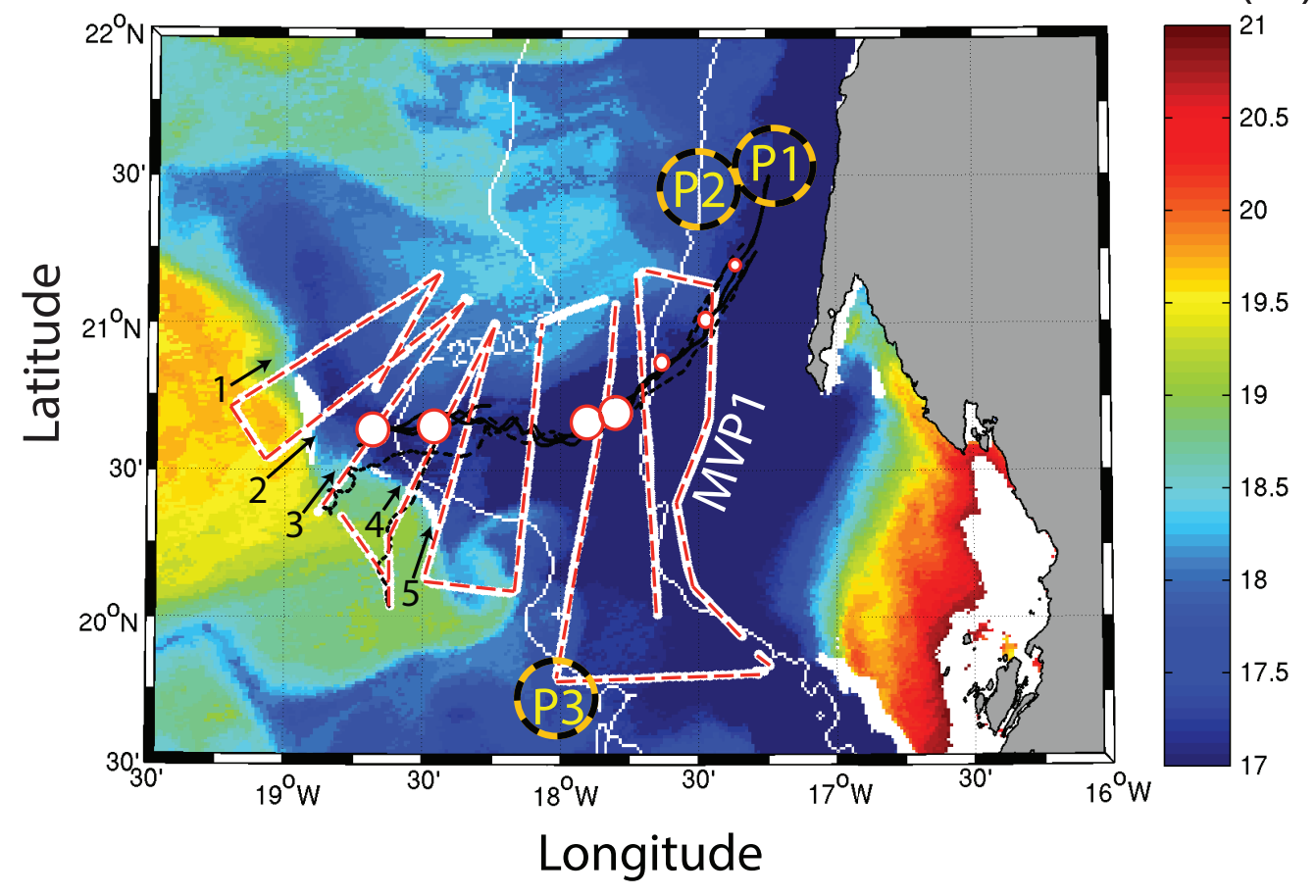

Figure 2: Sea surface temperature (SST) within the study region. Overlain (white/reddashed lines) is the ship-track for the MVP/VM-ADCP survey of the primary filament (MVP1) within which Patch 1 was conducted. Legs 1-5 for which detailed results are presented in Fig. 6 are labelled accordingly. The initial location of each patch experiment (labelled P1, P2 and P3, respectively) where the $\mathrm{SF}_{6}$ was released are indicated by the orange/black dashed circles. Note that the time that passed between P1 and P3 exceeded 3 weeks and thus the SST field, which corresponds to April 27 and thus towards the end of $\mathrm{P} 1$, evolved significantly by the time that P3 was initiated. The white circles (red outlines) along the ship track during MVP1 indicate the magnitude of the mismatch between the predicted new production based on available nutrients and the observed new production. 
out the cruise to enable the identification of the surface temperature fronts that marked the edge of the filaments. Coverage throughout the cruise was generally unimpeded by cloud cover. Data are derived from AVHRR with 1 $\mathrm{km}$ resolution; full details of processing are available at http://rsg.pml.ac.uk. Sea surface chlorophyll was also provided by NEODAAS derived from ocean colour data obtained through the Aqua sensor in the MODIS satellite.

Surface winds were obtained from Remote Sensing Systems Cross-Calibrated Multi-Platform (CCMP) product at a horizontal resolution of $0.25^{\circ}$.

\subsection{Biological measurements: new production estimates}

In order to make estimates of the new production, routine measurements of nutrients, primary production, f-ratios and plankton community were undertaken during both patch 1 and patch 3 from discrete water samples. The water samples were collected before dawn using Niskin bottles mounted on the CTD rosette frame at generally eight depths from which at least six included the euphotic layer and one was at the top five meters. Nutrient measurements of silicate, phosphate, nitrate, nitrite and ammonia where measured colorimetrically using a Bran and Luebbe AAIII segmented flow autoanalyzer (Woodward and Rees, 2001). Primary production was estimated from six light depths $(1,7,20,33,55$ and $97 \%$ of incident light) and distributed into triplicate $60 \mathrm{ml}$ polycarbonate bottles and inoculated with $\sim 10 \mu \mathrm{Ci}{ }^{14} \mathrm{C}$-bicarbonate. Incubations were performed in on-deck incubators under simulated in-situ light conditions and temperature controlled by surface seawater. Experiments were terminated after 24 hours by sequential filtration through 2 and $0.2 \mu \mathrm{m}$ Supor 200 membrane filters for particulate organic production. Samples were fumed with $\mathrm{HCl}$ prior to onboard liquid scintillation counting. Water samples from the same depths were used for quantifying the phytoplankton and microzooplankton community composition and abundance from microscopic analysis of samples preserved with Lugol's iodine. Cells were identified to species-level where possible in accordance with Tomas 2006 and assigned to three functional groups (Diatoms (centric and pennate), Dinoflagellates and Flagellates). The conversion from cell numbers to biomass was based on volumes according to geometric shapes and formulae of Olenina et al. (2006) and of Menden-Deuer and Lessard (2000).

Even under upwelling conditions, nitrification, the sequential oxidation of $\mathrm{NH}_{4}^{+}$through $\mathrm{NO}_{2}^{-}$to $\mathrm{NO}_{3}^{-}$, can make a significant contribution to $\mathrm{NO}_{3}^{-}$, assimilation in the surface ocean (Clark et al., 2011). This complicates the 
new production paradigm, where:

$$
\text { Newproduction }=f-\text { ratio } \times \text { Primary Production }
$$

because $\mathrm{NO}_{3}^{-}$regenerated within the photic zone cannot be equated to new nitrogen. Therefore, f-ratio determinations do not equate to new production (Yool et al., 2007) unless simultaneous measurements are made of nitrification and $\mathrm{N}$-assimilation $(\rho \mathrm{N})$. Such measurements are rarely done (Fernández I. and Raimbault, 2007; Fernández et al., 2009), but have demonstrated that nitrification can provide between $2 \%$ and $100 \%$ of phytoplankton $\mathrm{NO}_{3}^{-}$demand. In this study, we address this aspect by simultaneously assessing $\mathrm{N}$-assimilation and nitrification processes, and have adjusted f-ratio determination to correct estimates of new production for $\mathrm{NO}_{3}^{-}$derived from nitrification:

$$
F_{\text {nit }}-\text { ratio }=\frac{\left[\rho N O_{3}^{-} \times\left(1-\operatorname{regNO} O_{3}^{-}\right)\right]}{\left(\rho N O_{3}^{-}+\rho N H_{3}^{-}\right)}
$$

A brief description of methods is provided here; the reader is referred to Clark et al. (2006, 2007, 2011, 2016) for comprehensive details. Nitrogen assimilation and nitrification experiments were undertaken on near surface waters $(5 \mathrm{~m})$ to allow estimations of in-situ $\mathrm{f}_{n i t}$-ratios and new production estimates. For determination of $\mathrm{N}$-assimilation, seawater samples were collected into triplicate clear polycarbonate bottles and amended with either $\mathrm{N}^{15}-\mathrm{NO}_{3}^{-}$ or $\mathrm{N}^{15}-\mathrm{NH}_{4}^{+}$at approximately $10 \%$ of ambient concentrations according to Clark et al. (2011). Bottles were transferred to the on-deck incubators for 3 hours, after which they were filtered onto $25 \mathrm{~mm}$ GF/F filters. Filters were stored frozen until return to the shore based laboratory where they were dried at $50^{\circ} \mathrm{C}$ for 12 hours. $\mathrm{N}^{15}$ atom and particulate nitrogen concentration were determined using continuous flow stable isotope mass spectrometry (Owens and Rees, 1989) and rates of uptake corrected for isotope dilution (Clark et al., 2011). Rates of nitrification were determined using isotope dilution methods. $5 \mathrm{~L}$ of unfiltered seawater collected pre-dawn was amended with $\mathrm{N}^{15} \mathrm{O}_{2}^{-}\left(\mathrm{NH}_{4}^{+}\right.$oxidation studies $)$or $\mathrm{N}^{15}-\mathrm{NO}_{3}^{-}$( $\mathrm{NO}_{2}^{-}$oxidation studies).

Following the addition of $\mathrm{N}^{15}$, samples were mixed and triplicate $500 \mathrm{ml}$ samples were removed from each $5 \mathrm{~L}$ volume for the determination of preincubation $\mathrm{N}$ concentration and isotopic enrichment. 2.4L of the remaining $\mathrm{N}^{15}$ enriched seawater was incubated on deck for an average of 9 hours during day light. At the end of the incubation period, samples were filtered through $\mathrm{GF} / \mathrm{F}$ filters and triplicate $500 \mathrm{ml}$ volumes were used for the determination 
of post-incubation $\mathrm{N}$ concentration and $\mathrm{N}^{15}$ enrichment. Nitrification samples were collected by solid phase extraction, stored frozen and processed in the land based laboratory. Samples were eluted from SPE columns and deuterated internal standards were added for sample quantification. Samples were purified by HPLC and analysed by GCMS. N-regeneration rates were derived from end-points using the Blackburn-Caperon model Blackburn (1979); Caperon et al. (1979).

\subsection{New production budget}

After nutrients are upwelled to the euphotic zone on the shelf, water is advected offshore within the mesoscale filaments depicted in Fig. 1. Nutrients are drawn down by new production, depleting the available nutrients unless additional nutrients are supplied laterally from outside the filament or from the substantial resevoir beneath the thermocline.

All nutrient data were subsequently averaged for the euphotic layer to calculate a $\mathrm{NO}_{3}^{-}$based budget during the Lagrangian experiments. The euphotic layer increased from $35 \mathrm{~m}$ at the start of patch 1 to $60 \mathrm{~m}$ on the last day. The euphotic layer was in all occasions shallower than the mixed layer. $\mathrm{A} \mathrm{NO}_{3}^{-}$budget for the euphotic layer was calculated as $\Delta$ Ambient $\mathrm{NO}_{3}^{-}=$ $\mathrm{NO}_{3}^{-}$Uptake + VerticalNO $\mathrm{N}_{3}^{-}$Fluxes. Horizontal contributions are ignored on the basis that nutrient concentrations were lower outside the filament and would therefore act to remove rather than supply nutrients to the filament in which the Lagrangian experiment was performed. From the estimates of $\mathrm{NO}_{3}^{-}$Uptake and the observed C:N stoichiometry calculated as Total POC / Total PON we estimate the theoretical new production that could have been supported by the observed drop in ambient nitrate concentrations compensated by the observed vertical nitrate fluxes into the euphotic layer.

Vertical $\mathrm{NO}_{3}^{-}$fluxes were estimated as the sum of the vertical turbulent diffusive flux (described above), and the vertical transport from Ekman pumping. The Ekman pumping velocity was estimated from the wind stress curl (RSS CCMP v2.0, Remote Sensing Systems, www.rmss.com) as

$$
w_{e}=\frac{1}{\rho_{w}}\left(\Delta \times \frac{\tau}{f}\right)
$$

where $\rho_{w}$ is the density of seawater, $f$ is the coriolis frequency and $\tau$ is the wind stress vector. The total nutrient flux to the euphotic zone arising from turbulent fluxes and Ekman pumping is given by 


$$
\text { VerticalNO } \mathrm{O}_{3}^{-} \text {Fluxes }=K_{z} \frac{\partial C}{\partial z}+w_{e} C
$$

\section{Results}

We demonstrate here that the new production occurring offshore within a mesoscale filament required additional nutrients than were supplied by initial upwelling near the coast. We present results in three subsections to highlight 1) the discrepancy between new production and nutrient supply within the largest filament that was the focus of the first tracer release experiment (Patch 1) and that 2) the edges of the filament within which Patch 1 was conducted were susceptible to submesoscale instabilities due to the formation of regions with high local Rossby number. Direct evidence of the intense vertical circulations arising due to the emergence of submesoscales is provided by 3) direct evidence from Patch 2 for the rapid subduction of $\mathrm{SF}_{6}$ by intense vertical motions at a submesoscale front, and the direct measurement of the intense vertical velocities by a drifting ADCP as it crossed a submesoscale front for which evidence is obtained from a co-located drifting Wirewalker equipped with a profiling CTD.

\subsection{Patch 1: Nutrient concentrations and new production estimates in an upwelling filament}

Patch 1 began at $t=112.1$ with the injection of $\mathrm{SF}_{6}$ into the surface mixed layer and the release of the drogued drifters. The drifters, and thus the water parcel that was sampled throughout the following 7 days with CTD, water samples and microstructure profiling, were located within the upwelled water approximately $30 \mathrm{~km}$ inshore of the front when defined by the position of the $18.15^{\circ} \mathrm{C}$ isotherm estimated from the AVHRR data (Fig. 4a).

During the two days prior to the release of the tracer, a transect was completed perpendicular to the coast during which surface nitrate concentrations were measured in addition to a vertical profile to establish the horizontal and vertical nutrient distributions. The transect began offshore within the filament, traversed the stratified water that had become entrained around the meandering front, and finished within the coastal upwelled water (Fig. 3b). Nitrate concentrations were lowest $\left(\leq 2 \mathrm{mmol} \mathrm{m}^{-3}\right)$ within the stratified water, just offshore of the coastal front. Concentrations increased to $\approx 3 \mathrm{mmol}$ $\mathrm{m}^{-3}$ further offshore at the stations located within the upwelled water that 
had been advected offshore within the filament. Maximum concentrations were unsurprisingly observed where upwelling occurred, with surface concentrations of $\geq 7 \mathrm{mmol} \mathrm{m} \mathrm{m}^{-3}$ measured. The subsurface reservoir of nutrients was clearly evident in the vertical profile that indicated concentrations approaching $17 \mathrm{mmol} \mathrm{m}^{-3}$ below $40 \mathrm{~m}$ depth (Fig. 3a).

Throughout the week following the tracer release the drifter, and thus upwelled water, was advected offshore within the filament. However, whilst the track of the drifter largely followed the principal axis of the filament and described an anticyclonic trajectory, it's distance to the front when defined by the $18.15^{\circ} \mathrm{C}$ isotherm marking the outer edge of the filament decreased (Fig. 4). Beginning Patch 1 at a distance of $30 \mathrm{~km}$ from the front, the primary drifter encroached to within $10 \mathrm{~km}$ of the northern filament edge as the front turned towards the west. As the filament narrowed offshore and turned back towards a meridional orientation, the distance between the drifter and front decreased further until the water samples were essentially being collected from the frontal region.

The Dissolved Inorganic Nitrogen (DIN) pool in surface waters was dominated by $\mathrm{NO}_{3}^{-}(86 \% ; 94 \%)$, with $\mathrm{NH}_{4}^{+}(10 \% ; 2 \%)$ and $\mathrm{NO}_{2}^{-}(4 \% ; 4 \%)$ making only minor contributions. Concentrations of nitrate in newly upwelled surface waters (day 111) were $\approx 9.2 \mathrm{mmol} \mathrm{m}^{-3}$ and these reduced progressively as the filament advected offshore to $\approx 5.3 \mathrm{mmol} \mathrm{m}^{-3}$ at the end of the experimental period (day 119). The reduction in $\mathrm{NO}_{3}^{-}$concentrations was largely associated with high rates of primary production which also decreased with time from a maximum of $8.2 \mathrm{gC} \mathrm{m}^{-2} \mathrm{~d}^{-1}$ to $1.2 \mathrm{gC} \mathrm{m}^{-2} \mathrm{~d}^{-1}$ and were associated with surface chlorophyll concentrations which fell from $\approx 5.5$ to $0.9 \mu \mathrm{g}$ $\mathrm{m}^{-} 3$.

$\mathrm{N}$-assimilation and nitrification were measured simultaneously in the surface waters. High ambient $\mathrm{NO}_{3}^{-}$concentrations ensured that nitrification and assimilation were not directly coupled and turnover was relatively low, in contrast to $\mathrm{NH}_{4}^{+}$which cycled rapidly. Estimates of $\mathrm{F}_{n i t}$-ratio reflected proportionally higher $\mathrm{NO}_{3}^{-}$uptake in newly upwelled waters than in older waters as the values decrease from 0.62 on day 111 to 0.35 on day 119 .

The time at which the distance of the drifters from the front decreased coincided with the time at which the mismatch increased between predicted new production based on the initial supply of nutrients from the coastal upwelling and the observed new production. Immediately following upwelling at the coast, nitrate concentrations of $8 \mathrm{mmol} \mathrm{m}^{-3}$ supported equivalently high primary production of $8.2 \mathrm{gCm}^{-2}$ day $^{-1}$. Throughout the seven days 


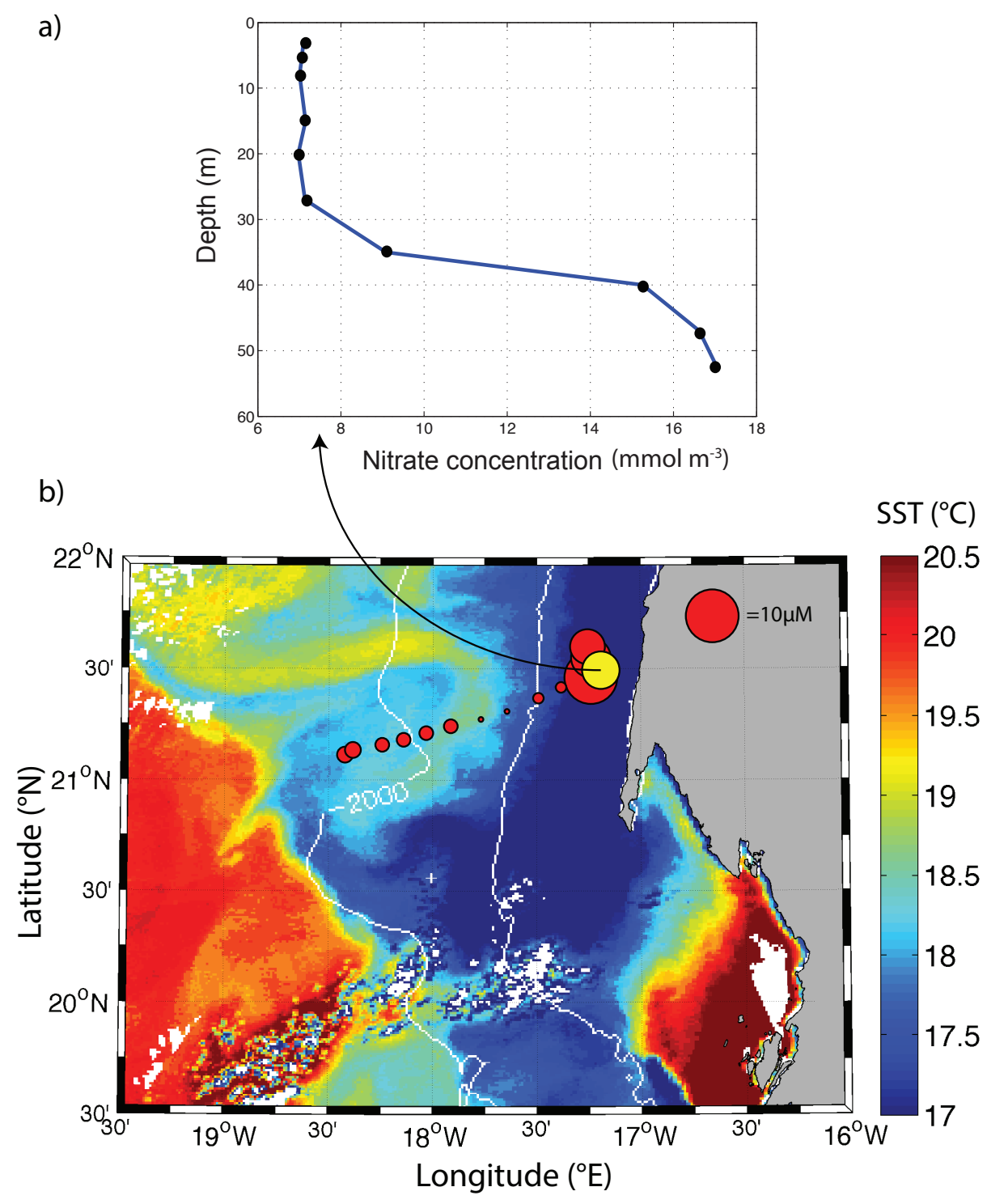

Figure 3: a) Vertical profile of nitrate concentration at the location indicated by the yellow circle in a), indicating the SST $\left({ }^{\circ} \mathrm{C}\right)$ throughout study region during day 109 and the surface nitrate concentration $(3 \mathrm{~m}$ depth) represented by the red circles. The size of the red circles indicate the nitrate concentration. The satellite passed overhead during the night-time of day 109 (20th April, 2009) at the time when the stations furthest inshore were sampled. 
for which the patch was tracked, however, the percentage of primary production that was attributable to the observed nitrate decline and vertical fluxes (computed from the daytime MSS profiles) reduced from 80-90\% near the coast and on the shelf to $\sim 60 \%$ four days later as the drifters moved towards the northern edge of the filament.

The stations on the shelf (corresponding to the first four days of Patch 1) exhibited daily ambient $\mathrm{NO}_{3}^{-}$decreases between $0.7-1.6 \mathrm{mmol} \mathrm{m}{ }^{-3}$ and daily vertical $\mathrm{NO}_{3}^{-}$fluxes ranging from 0.05 to $0.1 \mathrm{mmol} \mathrm{m}^{-3} \mathrm{day}^{-1}$ both terms balancing the New production mediated $\mathrm{NO}_{3}^{-}$decline $\left(1.2-2 \mathrm{mmol} \mathrm{m}^{-3}\right.$ day $\left.^{-1}\right)$. On subsequent days when the drifters were closer to the filament edge, daily ambient $\mathrm{NO}_{3}^{-}$decreases and vertical fluxes totalling 0.1-0.3 mmol $\mathrm{m}^{-3}$ were not sufficient to explain the New production requirements of $0.3-$ $0.7 \mathrm{mmol} \mathrm{m}^{-3}$ day $^{-1} \mathrm{NO}_{3}^{-}$. In both environments (on shelf and inside the filament), the turbulent vertical fluxes of $\mathrm{NO}_{3}^{-}$were of similar magnitude and corresponded to $\approx 10 \%$ of the New production requirements. On the shelf, the vertical fluxes were characterised by smaller $K_{z}$ but larger vertical nitrate gradients than inside the filament (Fig. 4c,f).

Nutrient supply by Ekman pumping was negligible; the region within which the filament was located was subjected to very weak downwelling velocities of $\leq 1 \mathrm{~m}$ day $^{-} 1$ based on observed winds during day 116 . The prevailing wind field changed little in terms of direction or magnitude during the cruise as is normal for this region. Corresponding nutrient fluxes were estimated across the region based on a nitrate concentration of $10 \mathrm{mmol} \mathrm{m}^{-3}$ were thus $<2 \mu \mathrm{mol} \mathrm{m}{ }^{-2}$ day $^{-1}$ (fig. 5). As nitrate concentrations offshore within the filament were $<10 \mathrm{mmol} \mathrm{m}^{-3}$ (Fig. 2e) the estimated fluxes are an overestimate for the region within which the initial upwelling occurred. We further note that surface nutrient concentrations outside the filament were significantly lower than within it, precluding lateral advection of nutrients as the supply mechanism (fig. 3).

\subsection{Filament survey: Background context}

Following recovery of the drifters at the end of the Patch 1 Lagrangian experiment, the principal filament was surveyed with the MVP and the shipmounted VM-ADCP. Throughout the 4 days that were required to complete the survey the filament structure evolved and the results cannot strictly be viewed as synoptic. In particular, SST data indicate that the northern filament front in Fig. 6 migrated north and weakened throughout MVP1. In contrast, the front on the southern edge of the filament was typically more 

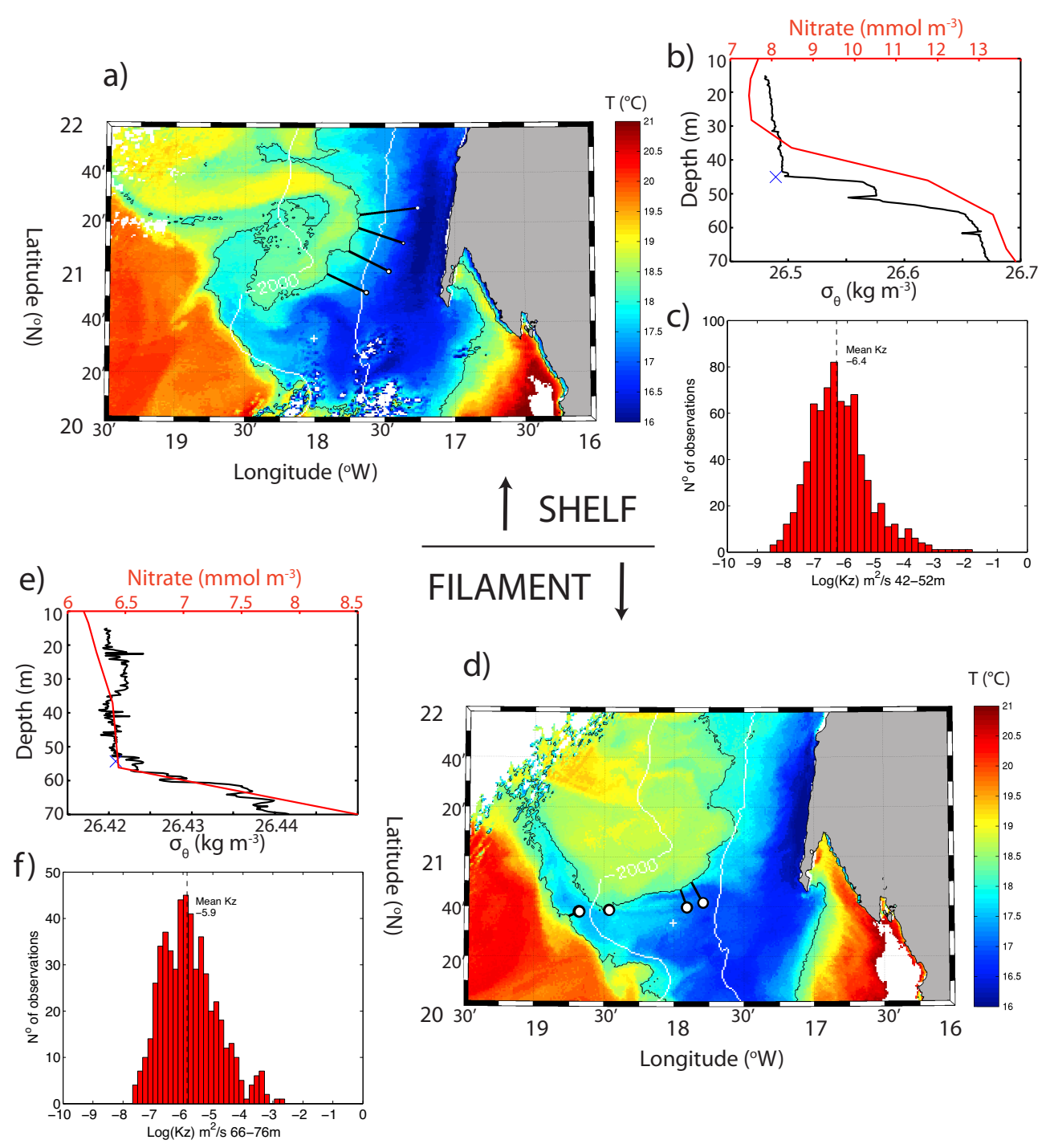

Figure 4: a) SST $\left({ }^{\circ} \mathrm{C}\right)$ throughout study region during day 112 and the position of the drogued drifter (black/white dots) over the shelf relative to the nearest location of front at the filament periphery (black line, defined as $18.15^{\circ} \mathrm{C}$ isotherm), vertical profiles of b) nitrate concentration (red line), and $\sigma_{\theta}$ (black line) and c) histogram of diapycnal diffusivity, Kz, across the pycnocline in the shelf region, and d) SST during day 116 when the drifter was entrained into the filament. The corresponding vertical profiles of nitrate and $\sigma_{\theta}$ are shown in e) and $\mathrm{f}$ ) the diapycnal diffusivity across the pycnocline, now at 66-76m and thus more than $20 \mathrm{~m}$ deeper than on the shelf. The depths corresponding to the upper limit of the pycnocline are indicated by the blue crosses in b) and e). 


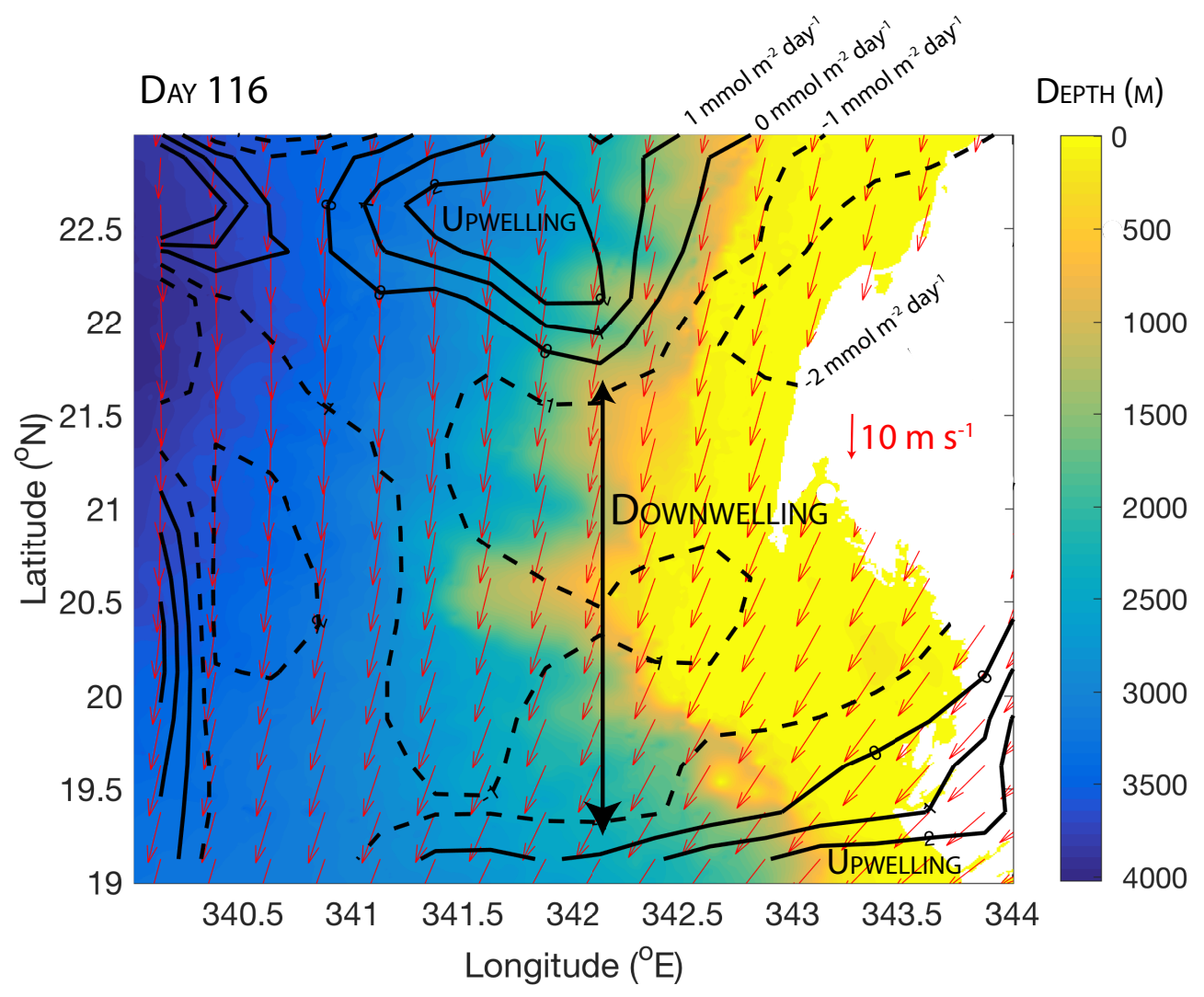

Figure 5: Nitrate flux due to Ekman pumping (contours) driven by the surface winds (red arrows) and assuming a spatially uniform nitrate concentration of $10 \mathrm{mmol} \mathrm{m}{ }^{-3}$. Downwelling is indicated by black dashed contours and upwelling by solid black lines. 
clearly defined and characterised by a stronger temperature gradient due to the greater influence of the warm SACW in the south.

The narrow horizontal extent of the filament at its furthest offshore position is revealed by the cooler, fresher water relative to that found at the ends of each cross-filament transect. The filament core is defined by water at the surface with temperature $\leq 19^{\circ} \mathrm{C}$ and salinity $\leq 36.0$. The lateral extent of the surface signature of the filament varies between each transect but is notably narrower where the filament approaches the limit of its offshore excursion to the west. Warmer, more saline water is found to the south of the filament due to the greater proportion of SACW.

The thermohaline gradients associated with the filament were density compensated to a large extent. Despite clear lateral gradients in both temperature and salinity, isopycnals remained largely horizontal across the filament. However, within localized regions at the filament edges isopycnals tend towards the vertical and, at the southern edge furthest offshore, outcrop. Observed where the warmest temperatures were located immediately adjacent to cool upwelled water, lateral density gradients exceeded $0.1 \mathrm{~kg}$ $\mathrm{m}^{-3}$, corresponding to a buoyancy gradient, $b_{x}$, of $1 \times 10^{-6} \mathrm{~s}^{-1}$. The near surface stratification results in small internal Rossby radii, $R o_{S M L}=N H / f$ where $N$ is the stratification of the surface mixed layer defined by the region of depth $H$ between the surface and the depth at which density increases by $0.1 \mathrm{~kg} \mathrm{~m}^{-3}$ relative to the surface. $R o_{S M L}$ is proposed to be the limiting length scale for submesoscale instabilities (Thomas et al., 2008), and here attained values of $R_{S M L}=2.8-3.9 \mathrm{~km}$. The largest values were found to the north where the near surface stratification was weaker.

The interior of the filament exhibited modest levels of chlorophyll-a fluorescence relative to the filament edges. In particular at the furthest offshore extent of the survey, fluorescence was at its lowest values of $\leq 0.1 \mathrm{~V}$ within a narrow band of $20 \mathrm{~km}$ horizontal extent coinciding with the cool, fresh water of the filament. Where the isopycnals outcropped, fluorescence $\geq 0.7 \mathrm{~V}$. Closer inshore, fluorescence exceeded $0.8 \mathrm{~V}$ at the southern ends of legs 4 and 5 where strong gradients in temperature and salinity occurred but for which there was no corresponding lateral density front. Chlorophyll concentrations were thus highest towards the periphery of the filament rather than within its core. 


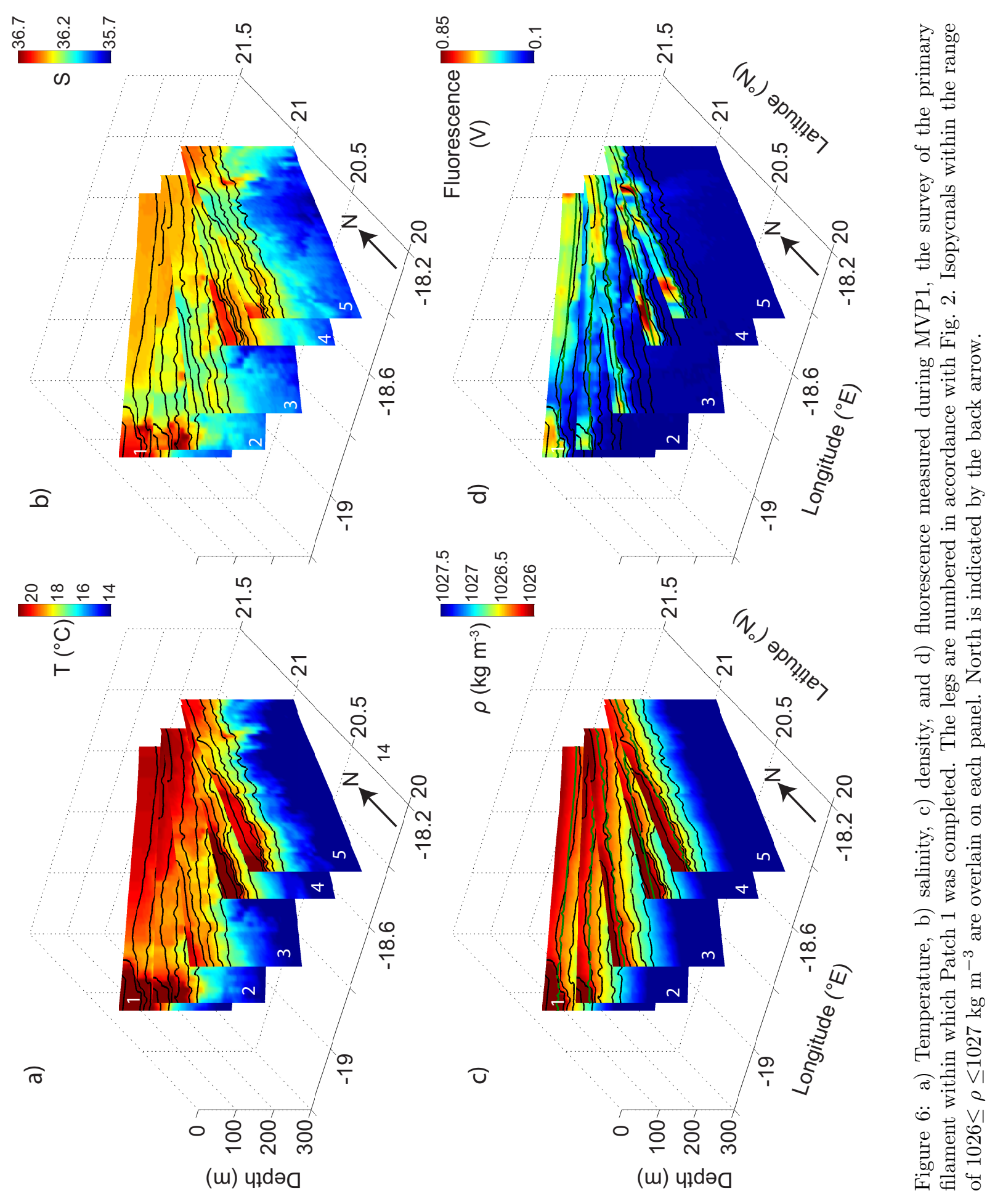




\subsection{Susceptibility to frontal instabilities}

To assess the susceptibility of the filament environment to submesoscale instabilities as a mechanism supplying nutrients in the absence of sufficient vertical turbulent entrainment or Ekman pumping, the hydrographic data obtained from the MVP was combined with the VM-ADCP data to provide information on the filament dynamical regime. In particular, as the Rossby number, Ro, approaches unity the flow is likely to become unstable and develop secondary a geostrophic motions. At the spatial scales of the filament front, in-situ measurements of both velocity components, $\mathrm{U}$ and $\mathrm{V}$, are required to compute their horizontal gradients. Given the inability of a single ship to neither measure gradients in both eastward and northward directions simultaneously, nor separately over a short enough time scale to eliminate the possibility of the flow evolving, we approximate the local relative vorticity, $\zeta=\frac{\partial v}{\partial x}-\frac{\partial u}{\partial y}$ using one velocity component only in the usual manner for such studies. Due to the dominance of the frontal flow and the design of the surveys to cross the filament perpendicular to the front orientation on each transect, VM-ADCP velocities were rotated to cross-front (flow orientated perpendicular to the front) and along-front (parallel to the front) components. The along-front velocity component was much larger than the cross-front component due to the dominance of the geostrophic flow, in particular at the southern end of legs 2 and 3 where the outcropping isopycnals were most pronounced (Fig. 7). Most notably, currents were directed offshore within the middle of the filament (approximately 30-60 km) before rotating to an inshore direction at the southern extent of each leg as the density front was crossed on the filament edge. During leg 2 , along-front velocity exceeded $0.4 \mathrm{~m} \mathrm{~s}^{-1}$, more than twice the maximum velocities directed normal to the front.

Largest $U_{\text {along }}$ (i.e. along-front flows) was observed on the southern edge of the filament where currents of $\sim 0.25 \mathrm{~m} \mathrm{~s}^{-1}$ were directed primarily eastward, i.e. towards the coast (Fig. 8a). In contract, offshore flow dominated currents within the filament and attained westward magnitudes larger than than the eastward frontal geostrophic flow in the south. Despite the absence of an equivalently strong frontal signature at the northern edge of the filament, it is likely that the weaker (compared to the eastward flow in the south) westward frontal flow reinforced the offshore flow within the filament. As a result of the superposition of the frontal flow on the mean offshore advection, there is thus no distinct dynamic signature associated with the northern front.

The strong vorticity associated with the frontal jets on the southern edge 


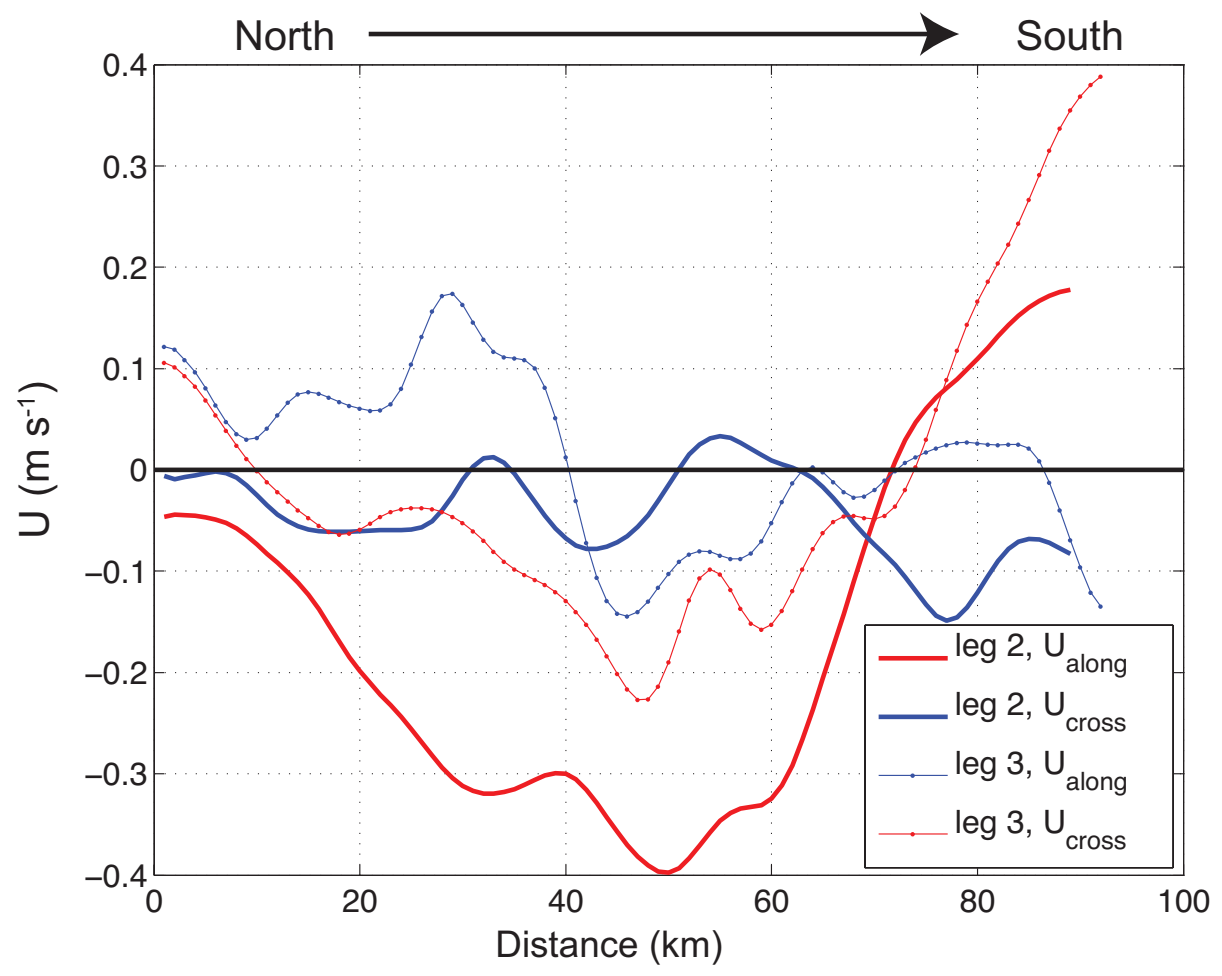

Figure 7: Along (red) and cross-front (blue) velocities during legs 2 (solid line) and 3 (dotted line). The along-front velocity component is estimated as the current directed perpendicular to the ship's direction of travel given the aim of crossing the front at right angles to its local orientation during each leg. Note the distinct increase in positive alongfront currents (directed to the south-east during legs 2 and 3) at the southern edge of each leg in accordance with that expected for thermal wind balance at the outcropping isopycnals. 


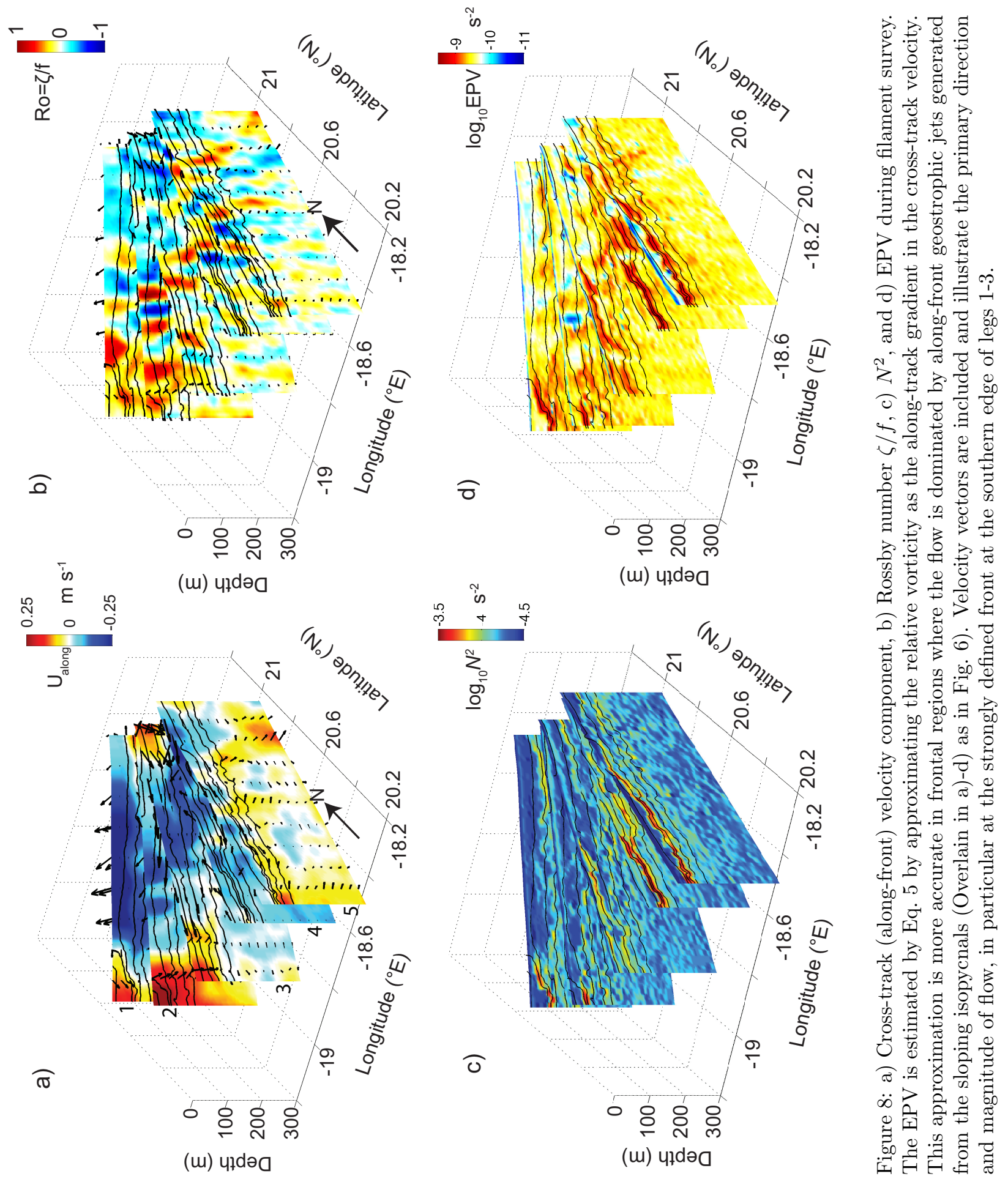


of the filament generated large Rossby numbers (Fig. 8b). Within several $\mathrm{km}$ of the outcropping isopycnals during legs 1 and 2 in particular, Ro approaches unity within localised regions just inside the front. Values of $R o$ are largely positive in accordance with the numerical modelling results of Mahadevan and Tandon (2006). The opposite sense of velocity veering across the northern edge of the filament generated weaker, negative $R o$ of $\sim 0.2$, possibly due to the weakened signature of the frontal flow by the mean offshore flow within the filament.

The extent to which the filament fronts are subject to frontogenesis from which submesoscale instabilities can subsequently emerge is quantified by the potential vorticity (PV) (Thomas and Lee, 2005), which depends on the relative vorticity of the flow, stratification and lateral density gradients. We thus consider the transects during MVP1 as cross-front sections for which $U_{\text {cross }}$, constitutes the along-front flow in a $2 \mathrm{D}$ approximation for $\mathrm{PV}, q_{2 d}$,

$$
q_{2 d}=\frac{1}{\rho_{o}}\left[\left(f-\frac{\partial U}{\partial y}\right) \frac{\partial \sigma_{\theta}}{\partial z}+\frac{\partial U}{\partial z} \frac{\partial \sigma_{\theta}}{\partial y}\right]
$$

Numerical simulations demonstrate that, within regions of negative PV, lateral density gradients within the surface mixed layer become symmetrically unstable, generating slantwise convection within submesoscale fronts (Thomas and Taylor, 2010). In our observations, lowest PV is found in the weakly stratified SML at the southern edge of leg 5 (Fig. 8c,d). Throughout the study region the $\mathrm{PV}$ is dominated by the influence of the stratification compared to that of relative vorticity or lateral density gradients. The strong front at the southern edge of legs 1 and 2 exhibit high PV within the strongly stratified sloping isopycnals despite the strong vorticity; the rotation of the velocity vectors across the front is in the sense to increase the vorticity term in Eq. 5 and thus the PV. In contrast the weaker stratification and opposite sense of rotation towards the northern front lowers the PV, rendering it more susceptible to frontogenetically induced instabilities and symmetric instability.

\subsection{Patch 2: Submesoscale circulations and subduction}

The mesoscale MVP/VM-ADCP survey of the primary filament demonstrated that it's edges were characterised by $O(1)$ Rossby number and therefore susceptible to the development of submesoscale instabilities (Molemaker et al., 2005) despite not providing any direct evidence of their role. Immediately following the large-scale survey and Patch 1, Patch 2 targeted what 
appeared to be an emerging filament. The drifters were deployed close to an upwelling front across which temperature increased from $17^{\circ} \mathrm{C}$ to nearly $19^{\circ} \mathrm{C}$ in less than $10 \mathrm{~km}$ (Fig. 9). The front was also demarcated by high chlorophyll concentrations on the northern (warm) side of the front, consistent with local upwelling supplying nutrient rich water to the surface and stimulating new production.

An initial survey prior to $\mathrm{SF}_{6}$ nighttime mapping revealed strong cyclonic vorticity within the surface layers; currents within the emerging filament were directed towards the filament edge where they rotated to become aligned with the front, presumably due to the influence of the along-front jet observed in the mesoscale filament survey (Fig. 9a). The vorticity signature of the front was much more pronounced than during MVP1 where the dynamic signature of the front on the northern edge of the filament was obscured. The strongest vorticity was observed as the ship passed through the northern front from the cold water into the warmer, chlorophyll-rich water at $18^{\circ} \mathrm{W}, 21^{\circ} 30^{\prime} \mathrm{N}$. Assuming that the rotation of the velocity at $26 \mathrm{~m}$, which is the shallowest bin for which good data were available, was dominated by the frontal current we estimate the $2 \mathrm{D}$ vorticity in the similar manner to described above. The observed velocities are rotated to be along and across-track and the crossfrontal gradient in along-front velocity used to estimate $\zeta$. Ro $\geq 1$ almost everywhere along the northern half of the eastern leg in Fig. 9a but reach a maximum (absolute) value of $R o=-6.6$ at the end of the leg where along-front velocities increase $\geq 0.1 \mathrm{~m} \mathrm{~s}^{-1} \mathrm{~km}^{-1}$.

As with Patch 1, a quantity of $\mathrm{SF}_{6}$ was released following deployment of the Wirewalker drifter. The tracer was initially constrained within a patch of approximately $5 \times 5 \mathrm{~km}$ horizontal extent but 24 hours later had become elongated in a north-east/south-west direction (Fig. 9d). More significantly, the $\mathrm{SF}_{6}$ concentration measured at the ship's intake at $4 \mathrm{~m}$ depth over the same 24 hour period from $t=128$ to $t=129$ decreased by an order of magnitude from $10^{3}$ fmol $^{-1}$ to $10^{2} \mathrm{fmol}^{-1}$ (Fig. 9). Water samples taken from a CTD profile indicated that the $\mathrm{SF}_{6}$ had been subducted out of the upper $50 \mathrm{~m}$ into the underlying stratification and elongated into a narrow filament. The vorticity signature and vertical current shear, $\partial U / \partial z \geq 3 \times 10^{-3} \mathrm{~s}^{-1}$, remained coherent throughout the upper $100 \mathrm{~m}$. Given the biogeochemical objectives of the cruise to monitor the primary production within the upwelled water, the experiment was subsequently terminated.

Direct evidence of the rapid vertical velocities implicated in the rapid subduction of the $\mathrm{SF}_{6}$ were obtained from the drifting ADCP. Following 


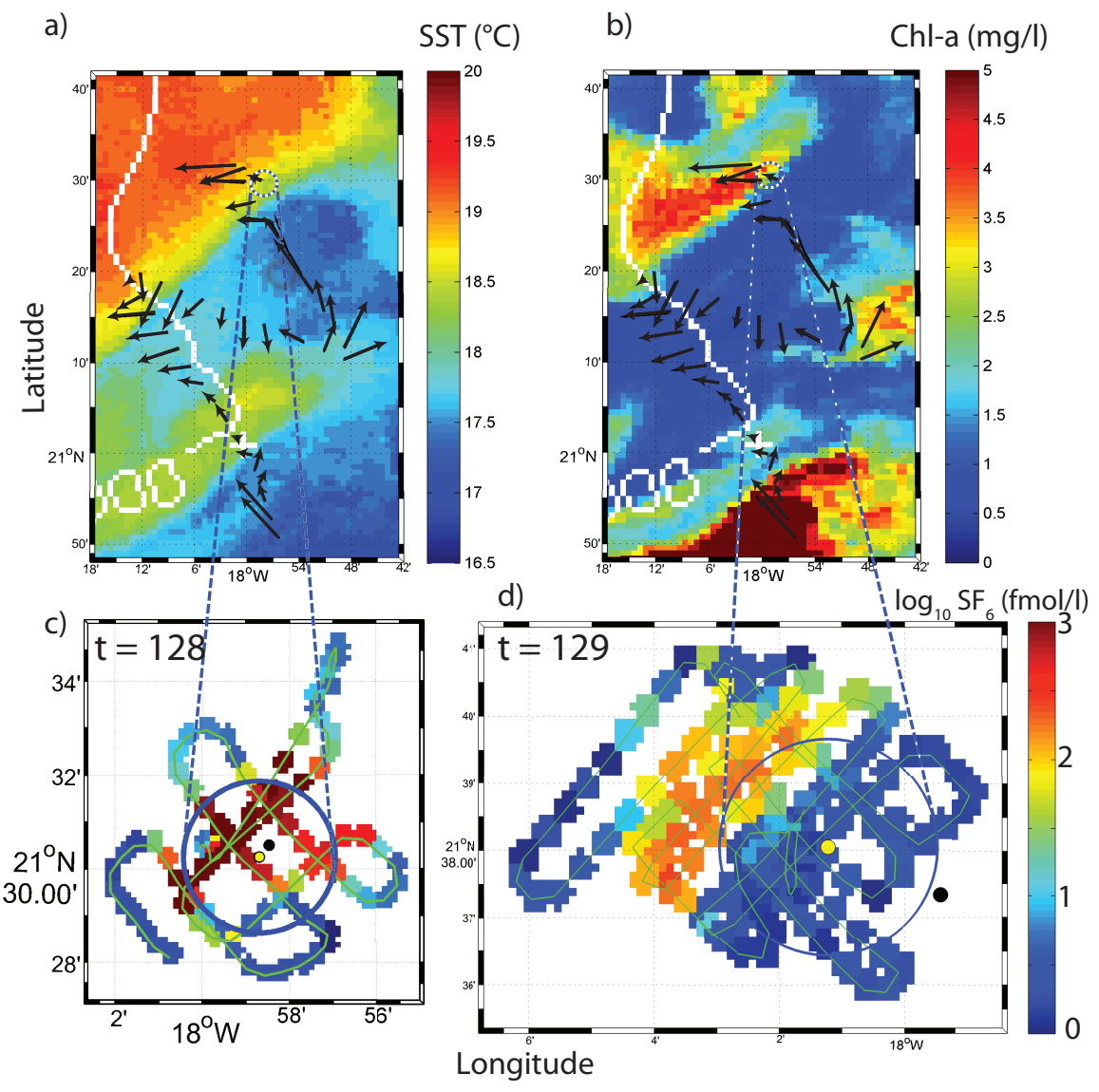

Figure 9: a) Sea surface temperature and b) chlorophyll-a within the immediate surroundings of the $\mathrm{SF}_{6}$ release location during Patch 2, and the surface concentration of $\mathrm{SF}_{6}$ at $\mathrm{c}$ ) $t=128$ following release and d) $t=129$. Note that the $\mathrm{SF}_{6}$ concentration scale is logarithmic. Surface velocity vectors in a) and b) correspond to a depth of $16 \mathrm{~m}$. 
their release, the Wirewalker and drifting ADCP twice approached the front depicted in Fig. 9. On each occasion the drifter measured an increase in temperature (and decrease in density) at the same time as persistent, coherent downward velocities of $\geq 4 \mathrm{~mm} \mathrm{~s}^{-1}$, equating to $\geq 350 \mathrm{~m} \mathrm{day}^{-1}$ (Fig. 10). The drifters remained within the downwelling current for approximately 1-2 hours before being advected back out of the front into the cooler filament water. As the drifters did not completely cross the front, they did not have the opportunity to measure the upwelling that would be expected as the return part of the thermally direct overturning circulation associated with the submesoscale front; numerical simulations demonstrate that downwelling occurs on the cold side of the front and upwelling on the warm side (Mahadevan and Tandon, 2006; Thomas and Lee, 2005). The maximum observed downwelling velocity occurred at $y=130.95$ as the drifters reached the front as evidenced by strongly sloping isotherms measured by the Wirewalker. Temperature increased from $16.8^{\circ} \mathrm{C}$ to $18^{\circ} \mathrm{C}$ within 2 hours and $w$ reached $8 \mathrm{~mm} \mathrm{~s}^{-1}$ at a depth of $60 \mathrm{~m}$, i.e. below the surface as suggested by Mahadevan and Tandon (2006).

\section{Discussion}

\subsection{Submesoscale instabilities at the edge of upwelling filaments}

The edges of mesoscale filaments created in response to coastal upwelling in an eastern boundary current have been demonstrated in numerical simulations to be highly susceptible to submesoscale instabilities (Capet et al., $2008 \mathrm{a}, \mathrm{b})$. The mechanism triggering the cascade of energy to smaller scale motions from an initial geostrophically balanced state is surface-intensified frontogenesis where surface horizontal density gradients are intensified by a confluent flow field. Local regions of high Rossby number emerge and permit the development of secondary instabilities that manifest themselves as intense vertical circulations at fronts, with downwelling on the cold side of the front and upwelling on the warm side. In our observations, the destabilisation of the front encircling the filament may have been accelerated by wind stress blowing in the direction of the along-front jet and generating a nonlinear Ekman transport that would advect cold fluid over the front to the warm side, triggering convective instabilities and further enhancing the break down in geostrophic balance. The process is intermittent and spatially localised. The resulting new production facilitated by the injection of nutrients is known to be episodic at timescales commensurate with the ephemeral 


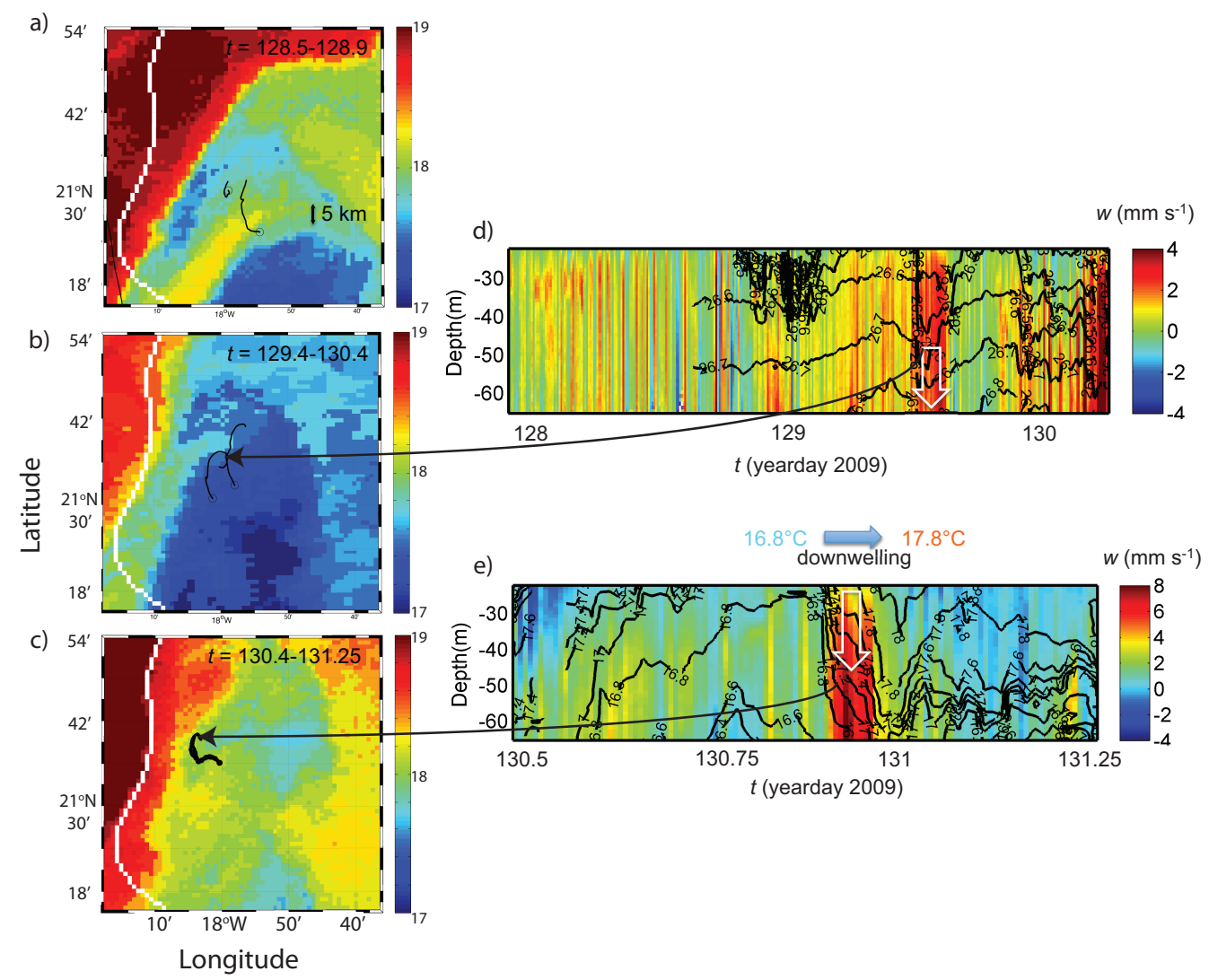

Figure 10: SST during days a) 128,b) 129 and $c$ ) 130, and vertical velocities measured by the drifting ADCP over the periods $d$ ) $t=128-130.25$ and $e$ ) $t=130.5-131.25$. The intense downwelling at $t=129.7$ in $d$ ) and 130.9 in $e$ ) occur at precisely the time that the drifter passed nearest the front observed in the remote sensing images (indicated by the long black arrows between $b)-d$ ) and $c$ ) $-e$ ). The drifter track for the period over which the SST data were collected in each image is indicated in $a)-c$ ) by the black line. Black lines in d) and e) correspond to isopycnals and isotherms, respectively. 
nature of submesoscales themselves and spatially patchy (Levy et al., 2012). The patchy production is particularly pronounced in the remote sensing image for chlorophyll-a depicted by Fig. 1.

Our observations are entirely consistent with the dynamic environment elucidated by Capet et al. (2008a,b) and who further suggest that their effects on biogeochemical exchange may be quite important. They are also in direct contrast to the findings of Gruber et al. (2011) who propose, on the basis of an eddy resolving (but not submesoscale-resolving) model and satellite observations, that within the same upwelling region as we have presented biological production is actually suppressed. The towed CTD and VM-ADCP surveys highlighted that the filament periphery was characterised by strong vorticity associated with the frontal jets and order unity Rossby numbers. The mesoscale environment is thus susceptible to frontogenesis and the development of submesoscale instabilities that are demonstrated by numerical simulations to be intermittent in time and space, and to manifest themselves as intense vertical velocities in narrow filaments of strong cyclonic vorticity (Mahadevan and Tandon, 2006). The vertical velocities measured by the drifting ADCP as it approached a temperature front during Patch 2, and the rapid subduction of tracer, provide direct evidence of submesoscale vertical circulations in teh observations presented here. Accompanied by pronounced cyclonic vorticity for which there has been demonstrated a strong preponderance in simulations (e.g. Levy et al. (2001); Mahadevan and Tandon (2006)), the encountering of an intense downwelling flow on the cold side of the front indicates that there is almost certainly an accompanying upwelling on the warm side of the front. We did not observe the upwelling, however, because the drifters did not cross front to the warm side.

Two outstanding issue remain; firstly, where the additional nutrients were fed into the system and secondly, how did the nutrients upwelled on the warm side of the front cross to the inside of the filament where they were able to stimulate new production? With respect to the location of the instabilities and resupply of nutrients, the new production was observed to be higher than expected at the position where the front changed its orientation from meridional to zonal. The importance of the orientation lies in the effectiveness of the wind stress to generate a cross-front Ekman buoyancy flux by blowing down front. Through so doing, the wind stress interacts with the low frequency vorticity of the frontal jet to advect dense surface water across the front, thereby triggering convective instabilities that intensify the frontal circulations. The anatomy of the filament would indicate that the persistent 
northerly wind stress in the Cap Blanc region was (and always will be given the ubiquity of the wind direction) aligned with the frontal jet in two primary locations; firstly, along the initial upwelling front that runs parallel to the coast and to the east of which in our observations the $\mathrm{SF}_{6}$ was released. Secondly, a southward flowing jet was observed in Fig. 8 on the southern side of the filament at its furthest offshore extent and was laterally localized to the extent that the relative vorticity associated with the its horizontal, cross-front gradient, generated $O(1)$ Rossby number.

Despite the apparent inconsistency in the location at which the new production was enhanced and the frontal orientation that was largely perpendicular to the wind stress where excessive production was observed, we note that the nutrients upwelled along the filament periphery will be advected by the frontal jet, thereby becoming available to stimulate new production downstream of the injection location. There is thus a remote effect of the upwelling on new production when considered in an along-front sense. Secondly, new production will be stimulated nearer the front where the upwelled nutrients are concentrated. During the first half of Patch 1, the drifters and thus centre of the Lagrangian reference frame were located more than $30 \mathrm{~km}$ from the front and would not have been able to access the nutrients made available near the front by submesoscale instabilities. It was not until the drifters became entrained in the frontal flow on day 115 that our observations were made within a nutrient enriched region. The remote effect of submesoscales on new production has been discussed by Lévy et al. (2012) but refers to much longer timescales of variability that are more consistent with the oceanic gyres than with the short spatiotemporal scales discussed here. We have focussed on Patches 1 and 2 in this paper because the available data permit a degree of confidence in the interpretation of the results; during Patch 3 no MVP data were acquired and so we are not able to assess the susceptibility of the filament edges to submesoscale instabilities. However, Fig. 11 demonstrates that the mismatch within the southern filament was very small, implying that there was no influence of additional nutrients on new production. In contrast to Patch 1 , however, the Lagrangian reference frame in which the measurements were made was always far from the front. Secondly, the front was considerably weaker than the primary filament discussed earlier when viewed interns of the magnitude of SST gradients.

The mechanism by which nutrients upwelled on the warm side of the filament edge encroach into the filament is less clear. Satellite images of an upwelling filament within the Californian eastern boundary current system 

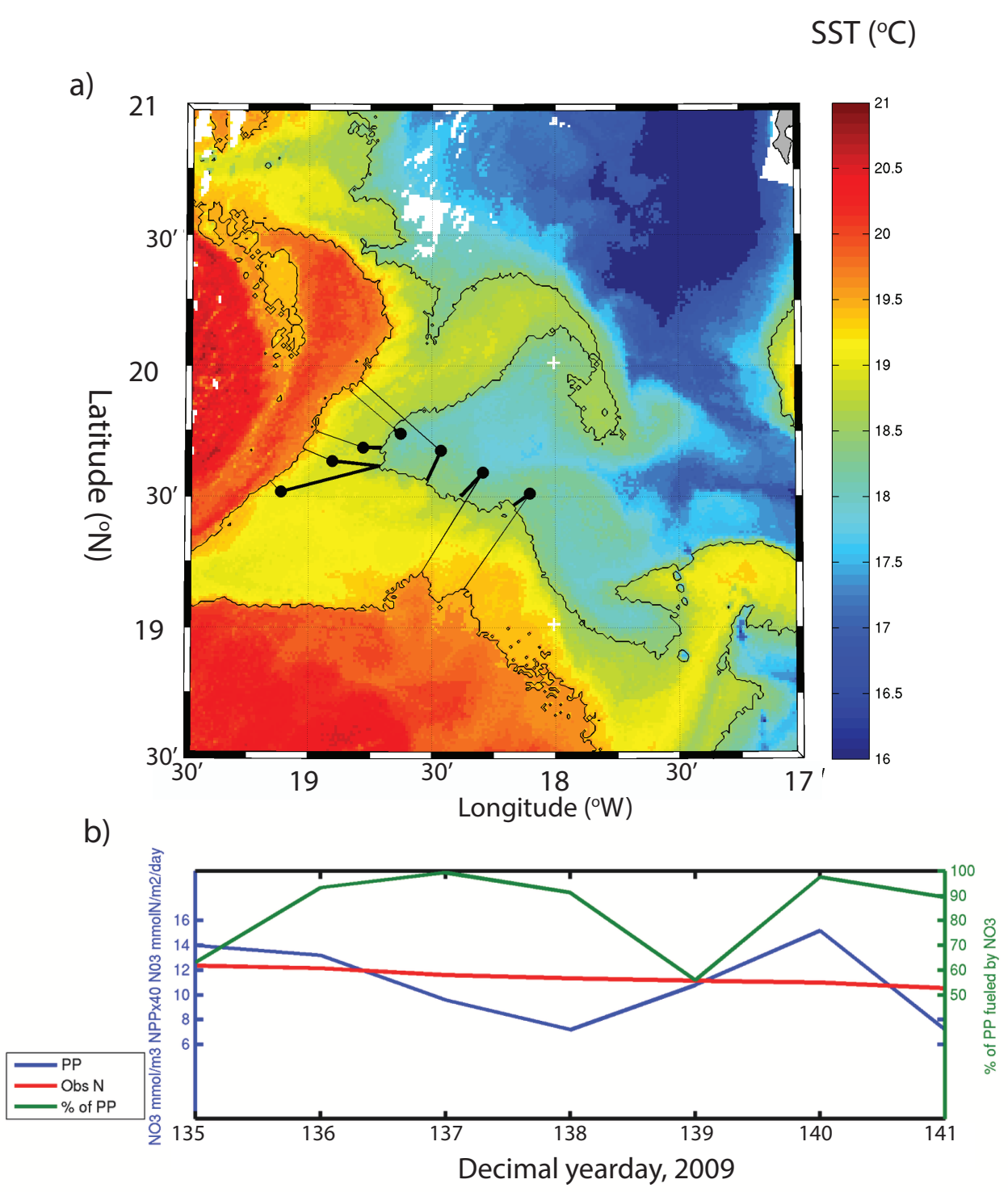

Figure 11: Summary of conditions during Patch 3, which was conducted further south and approximately 3 weeks after Patch 1 . a) SST $\left({ }^{\circ} \mathrm{C}\right)$ throughout study region of Patch 3 during day 137 and the position of the drogued drifter (black) relative to the nearest location of front at the filament periphery (black line, defined as $18.5^{\circ} \mathrm{C}$ isotherm); b) nitrate concentration (red line), new production (blue line) and the percentage of the new production that can be explained by the observed nitrate concentration (green line) throughout Patch 3. 
provide clear evidence of warm water filaments intruding into the main body of the filament (Figure 16 in Capet et al. (2008b)). As submesoscales are ephemeral and short-lived, the filaments decay and, in the case of nutrientrich filaments generated on the warm side of the front, diffuse the tracers that they contain into the surrounding water. Under such a scenario, the nutrients that we propose are brought to the surface by the intense circulations at the filament periphery would be made available within the colder upwelled water inside the front. Additional work is required in this area to evaluate the behavior and fate of the nutrients within a rapidly evolving dynamic system; Levy et al. (2012) discuss how the timescales of variability associated with submesoscale circulations may actually render them quite ineffective in stimulating new production as compared to mesoscales for which the supply of nutrients is lower but more persistent over biologically relevant timescales.

\section{Conclusions}

Observations made during a cruise to the eastern boundary current upwelling system off Cap Blanc indicate that nutrients upwelled to the euphotic zone inshore of the coastal front stimulate high levels of primary production. The coastal front develops mesoscale instabilities and forms filaments of upwelled water that extend several hundreds of kilometers offshore. As the nutrient-rich water was advected offshore within the filament, new production remained higher than can be explained by the locally available nutrients and vertical fluxes across the base of the euphotic layer. Specifically, only $60 \%$ of the new production could be explained by the local nutrient and vertical fluxes, implying that additional nutrients were being supplied to the interior of the filament.

A large-scale towed CTD and vessel-mounted ADCP survey of the filament within which the mismatch was observed indicate that the peripheral edges of the filament were characterized by strong relative vorticity and Rossby numbers approaching unity, rendering the frontal environment susceptible to the generation of submesoscale instabilities. The southern edge of the filament in particular was demarcated by a strong lateral buoyancy gradient and distinct frontal jet that flowed parallel to the outcropping isopycnals. Chlorophyll-a concentrations were patchy but intensified at the filament edges, consistent with the local injection of nutrients to the euphotic zone where lateral buoyancy gradients and vorticity were elevated. 
Direct evidence for the role played by submesoscales circulations was found during the second Lagrangian Patch experiment that aimed to study the draw-down of nutrients within a newly-forming filament of upwelled water. The $\mathrm{SF}_{6}$ tracer was injected at the surface immediately adjacent to a strong temperature front across which the horizontal velocity rotated cyclonically, generating negative Rossby numbers with an absolute magnitude of $\geq 5$ when local relative vorticity, $\zeta$, was approximated as the along-track gradient in cross-front velocity. Within 24 hours the tracer concentration had decreased by an order of magnitude due to its subduction out of the surface layers and become constrained within an elongated patch that aligned with the front. Over the two days for which the drifters were deployed, downwelling vertical velocities $\geq 350 \mathrm{~m}^{\text {day }}{ }^{-1}$ were observed on three separate occasions at the precise moment that they approached the front from the cold side. Thus the vertical velocities and tracer behaviour displayed the properties of thermally direct overturning circulations predicted by numerical simulations to occur within elongated filaments of negative vorticity.

It remains unclear where the nutrients are resupplied to the filament given the localized regions within which wind stress is aligned with the frontal currents. Whilst not the only mechanism capable of generating submesoscale instabilities within frontal regions, it remains the most likely explanation for the injection of nutrients that we observed. The effects on biological production are not localized to the sites of active submesoscale upwelling but may be remote due to the advection of nutrients down front by the geostrophic jet. Similarly, there is some evidence that the nutrients upwelled on the warm side make themselves available for new production within the mesoscale filament by becoming entrained in submesoscale filaments that intrude into the cold upwelled water. As the submesoscale features are ephemeral and comparatively short-lived, the nutrients that they contain thereafter become available within the main filament following their decay.

\section{Acknowledgements}

This work was funded by UK NERC grant NE/C517176/2. The authors thank the NERC Earth Observation Data Acquisition and Analysis Service (NEODAAS) for supplying data in this study. We thank the National Marine Facilities staff for their assistance in operating the MVP and the captain and crew of the RRS Discovery for their help throughout the D338 cruise. Torres 
was additionally supported by the NERC National Capability in Modelling programme at the Plymouth Marine Laboratory.

\section{References}

Barnes, S.L., 1994. Applications of the Barnes Objective Analysis Scheme. Part I: Effects of Undersampling, Wave Position, and Station Randomness. Journal of Atmospheric and Oceanic Technology 11, 1433-1448. doi:10.1175/1520-0426.

Blackburn, T.H., 1979. Method for measuring rates of NH4+ turnover in anoxic marine sediments, using a 15N-NH4+ dilution technique. Applied and Environmental Microbiology 37, 760-765.

Caperon, J., Schell, D., Hirota, J., Laws, E., 1979. Ammonium excretion rates in Kaneohe Bay, Hawaii, measured by a $15 \mathrm{~N}$ isotope dilution technique. Marine Biology 54, 33-40.

Capet, X., McWilliams, J.C., Molemaker, M.J., Shchepetkin, A.F., 2008a. Mesoscale to Submesoscale Transition in the California Current System. Part I: Flow Structure, Eddy Flux, and Observational Tests. Journal of Physical Oceanography 38, 29-43. doi:10.1175/2007JPO3671.1.

Capet, X., McWilliams, J.C., Molemaker, M.J., Shchepetkin, A.F., 2008b. Mesoscale to Submesoscale Transition in the California Current System. Part II: Frontal Processes. Journal of Physical Oceanography 38, 44-64. doi:10.1175/2007JPO3672.1.

Clark, D.R., Fileman, T.W., Joint, I., 2006. Determination of ammonium regeneration rates in the oligotrophic ocean by gas chromatography/mass spectrometry. Marine Chemistry 98, 121-130. doi:10.1016/j.marchem.2005.08.006.

Clark, D.R., Miller, P.I., Malcolm, E., Woodward, S., Rees, A.P., 2011. Inorganic nitrogen assimilation and regeneration in the coastal upwelling region of the Iberian Peninsula. Limnology and Oceanography 56, 16891702. doi:10.4319/lo.2011.56.5.1689.

Clark, D.R., Rees, A.P., Joint, I., 2007. A method for the determination of nitrification rates in oligotrophic marine seawater by gas 
chromatography/mass spectrometry. Marine Chemistry 103, 84-96. doi:10.1016/j.marchem.2006.06.005.

Clark, D.R., Widdicombe, C.E., Rees, A.P., Malcolm, E., Woodward, S., 2016. The significance of nitrogen regeneration for new production within a filament of the Mauritanian upwelling system. Biogeosciences 13, 28732888. doi:10.5194/bg-13-2873-2016.

Fernández, C., Farías, L., Alcaman, M., 2009. Primary production and nitrogen regeneration processes in surface waters of the Peruvian upwelling system. Progress in Oceanography 83, 159-168. doi:10.1016/j.pocean.2009.07.010.

Fernández I., C., Raimbault, P., 2007. Nitrogen regeneration in the $\mathrm{NE}$ Atlantic Ocean and its impact on seasonal new, regenerated and export production. Marine Ecology Progress Series 337, 79-92. doi:10.3354/meps337079.

Gruber, N., Lachkar, Z., Frenzel, H., Marchesiello, P., Münnich, M., McWilliams, J.C., Nagai, T., Plattner, G.K., 2011. Eddy-induced reduction of biological production in eastern boundary upwelling systems. Nature Geoscience 4, 787-792. doi:10.1038/ngeo1273.

Huntsman, S.A., Barber, R.T., 1977. Primary production off northwest Africa: the relationship to wind and nutrient conditions. Deep Sea Research 24, 25-33. doi:10.1016/0146-6291(77)90538-0.

Ikeda, M., Emery, W.J., 1984. Satellite observations and modeling of meanders in the California Current System off Oregon and northern California. Journal of Physical Oceanography 14, 1434-1450.

Lathuiliere, C., Levy, M., Echevin, V., 2010. Impact of eddydriven vertical fluxes on phytoplankton abundance in the euphotic layer. Journal of Plankton Research 33, 827-831. URL: http://www.plankt.oxfordjournals.org/cgi/doi/10.1093/plankt/fbq131, doi:10.1093/plankt/fbq131.

Levy, M., Ferrari, R., Franks, P.J.S., Martin, A.P., Rivière, P., 2012. Bringing physics to life at the submesoscale. Geophysical Research Letters 39, 1-13. doi:10.1029/2012GL052756. 
Lévy, M., Iovino, D., Resplandy, L., Klein, P., Madec, G., Tréguier, A.M., Masson, S., Takahashi, K., 2012. Large-scale impacts of submesoscale dynamics on phytoplankton: Local and remote effects. Ocean Modelling 43-44, 77-93. doi:10.1016/j.ocemod.2011.12.003.

Levy, M., Klein, P., Treguier, A.M., 2001. Impact of sub-mesoscale physics on production and subduction of phytoplankton in an oligotrophic regime. Journal of Marine Research 59, 535-565.

Li, Q.P., Dong, Y., Wang, Y., 2016. Phytoplankton dynamics driven by vertical nutrient fluxes during the spring inter-monsoon period in the northeastern South China Sea. Biogeosciences 13, 455-466. doi:10.5194/bg-13455-2016.

Loucaides, S., Tyrrell, T., Achterberg, E.P., Torres, R., Nightingale, P.D., Kitidis, V., Serret, P., Woodward, M., Robinson, C., 2012. Biological and physical forcing of carbonate chemistry in an upwelling filament off northwest Africa: Results from a Lagrangian study. Global Biogeochemical Cycles 26. doi:10.1029/2011GB004216.

Mahadevan, A., D’Asaro, E., Lee, C., Perry, M.J., 2012. Eddy-driven stratification initiates North Atlantic spring phytoplankton blooms. Science 337, 54-8. doi:10.1126/science.1218740.

Mahadevan, A., Tandon, A., 2006. An analysis of mechanisms for submesoscale vertical motion at ocean fronts. Ocean Modelling 14, 241-256. doi:10.1016/j.ocemod.2006.05.006.

Martínez-Marrero, A., Rodríguez-Santana, A., Hernández-Guerra, A., FraileNuez, E., López-Laatzen, F., Vélez-Belchí, P., Parrilla, G., 2008. Distribution of water masses and diapycnal mixing in the Cape Verde Frontal Zone. Geophysical Research Letters 35. doi:10.1029/2008GL033229.

McGillicuddy, D.J., Anderson, L.a., Bates, N.R., Bibby, T., Buesseler, K.O., Carlson, C.a., Davis, C.S., Ewart, C., Falkowski, P.G., Goldthwait, S.a., Hansell, D.a., Jenkins, W.J., Johnson, R., Kosnyrev, V.K., Ledwell, J.R., Li, Q.P., Siegel, D.a., Steinberg, D.K., 2007. Eddy/wind interactions stimulate extraordinary mid-ocean plankton blooms. Science (New York, N.Y.) 316, 1021-6. doi:10.1126/science.1136256. 
Menden-Deuer, S., Lessard, E.J., 2000. Carbon to volume relationships for dinoflagellates, diatoms, and other protist plankton. Limnology and Oceanography 45, 569-579. doi:10.4319/lo.2000.45.3.0569.

Meunier, T., Barton, E.D., Barreiro, B., Torres, R., 2012. Upwelling filaments off Cap Blanc: Interaction of the NW African upwelling current and the Cape Verde frontal zone eddy field? Journal of Geophysical Research 117, C08031. doi:10.1029/2012JC007905.

Molemaker, M.J., McWilliams, J.C., Yavneh, I., 2005. Baroclinic Instability and Loss of Balance. Journal of Physical Oceanography 35, 1505-1517. doi:10.1175/JPO2770.1.

Narimousa, S., Maxworthy, T., 1989. Application of a laboratory model to the interpretation of satellite and field observations of coastal upwelling. Dynamics of Atmospheres and Oceans 13, 1-46. doi:http://dx.doi.org/10.1016/0377-0265(89)90032-8.

Nightingale, P.D., Malin, G., Law, C., Watson, A.J., Liss, P.S., Liddicoat, M.I., Boutin, J., Upstill-Goddard, R.C., 2000. In situ evaluation of air-sea gas exchange parameterizations using novel conservative and volatile tracers. Global Biogeochemical Cycles 14, 373-387. doi:10.1029/1999GB900091.

Olenina, I., Hajdu, S., Edler, L., Andersson, A., Wasmund, N., Busch, S., Gobel, J., Gromisz, S., Huseby, S., Huttunen, M., Jaanus, A., Kokkonen, P., Ledaine, I., E. Niemkiewicz, 2006. Biovolumes and size-classes of phytoplankton in the Baltic Sea, in: Baltic Sea Environment Proceedings.

Osborn, T.R., 1980. Estimates of the Local Rate of Vertical Diffusion from Dissipation Measurements. Journal of Physical Oceanography 10, 83-89.

Owens, N.J.P., Rees, A.P., 1989. Determination of Nitrogen45 at Submicrogram Levels of Nitrogen Using Automated Continuous-flow Isotope Ratio Mass Spectrometry. Analyst 114, 1655-1657.

Perez-Rodriguez, P., Pelegrí, J.L., Marrero-Diaz, A., 2001. Dynamical characteristics of the Cape Verde frontal zone. Scientia Marina 65, 241-250.

Pinkel, R., Goldin, M.A., Smith, J.A., Sun, O.M., Aja, A.A., Bui, M.N., Hughen, T., 2010. The Wirewalker: A Vertically Profiling Instrument 
Carrier Powered by Ocean Waves. Journal of Atmospheric and Oceanic Technology 28, 426-435. doi:10.1175/2010JTECHO805.1.

Thomas, L.N., Lee, C.M., 2005. Intensification of Ocean Fronts by Down-Front Winds. Journal of Physical Oceanography 35, 1086-1102. doi:10.1175/JPO2737.1.

Thomas, L.N., Tandon, A., Mahadevan, A., 2008. Submesoscale processes and dynamics, in: Hecht, M.W., Hasumi, H. (Eds.), Ocean Modeling in an Eddying Regime, Geophysical Monograph Series, Volume 177. American Geophysical Union, Washington DC, pp. 17-38.

Thomas, L.N., Taylor, J.R., 2010. Reduction of the usable wind-work on the general circulation by forced symmetric instability. Geophysical Research Letters 37, 1-5. doi:10.1029/2010GL044680.

Woodward, E., Rees, A., 2001. Nutrient distributions in an anticyclonic eddy in the northeast Atlantic Ocean, with reference to nanomolar ammonium concentrations. Deep Sea Research Part II: Topical Studies in Oceanography 48, 775-793. doi:10.1016/S0967-0645(00)00097-7.

Yool, A., Martin, A.P., Fernández, C., Clark, D.R., 2007. The significance of nitrification for oceanic new production. Nature 447, 999-1002. doi:10.1038/nature05885. 